\title{
Biologicals in der Rhinologie - Individualisierte Konzepte der Zukunft
}

\section{Biologics in Rhinology - Forthcoming Personalized Concepts: the Future Starts Today}

\section{(ㄷ) (1) 우) $\ominus$}

Autor

Adam M. Chaker

Institut

Klinik für Hals-Nasen-Ohrenheilkunde und Zentrum für

Allergie und Umwelt, Klinikum rechts der Isar, Technische

Universität München

Schlüsselwörter

Rhinitis, Sinusitis, Rhinosinusitis, CRS, Biologica, Nasenpolypen, personalisierte Medizin

Key words

Rhinitis, Sinusitis, Rhinosinusitis, CRS, CRSwNP, Nasal Polyps, Biologics, Precision Medicine, Personalized Medicine

\author{
Bibliografie \\ DOI https://doi.org/10.1055/s-0043-123484 \\ Laryngo-Rhino-Otol 2018; 97: S142-S163 \\ (c) Georg Thieme Verlag KG Stuttgart · New York \\ ISSN 1615-0007
}

Korrespondenzadresse

Dr. med. Adam M. Chaker

HNO-Klinik und ZAUM

Klinikum rechts der Isar, Ismaninger Str. 22

D-81675 München

Tel.: ++49 894140 2370, Fax: ++49 8941409853

adam.chaker@tum.de

\section{ZUSAMMENFASSUNG}

Sinunasale Erkrankungen zählen mit zu den häufigsten chronischen Erkrankungen und führen zu einer erheblichen Störung der Lebensqualität, ein komorbides Asthma ist häufig. Trotz leitliniengerechter Therapie ist anzunehmen, dass mind. 20\% der Patienten ihre Erkrankungssymptome nicht adäquat kontrollieren können. Neben den etablierten chirurgischen und konservativen Therapieoptionen finden sich nun vielversprechende Therapieansätze, die bspw. mittels therapeutischer Antikörper mechanistisch gezielt in die Pathophysiologie der Erkrankungen eingreifen können. Die Auswahl der geeigneten Patienten durch geeignete Biomarker und die richtige Therapie zum richtigen Stadium der Erkrankung anbieten zu können, ist das Ziel stratifizierter Medizin und eine wichtige Perspektive für die HNO.

\section{ABSTRACT}

Chronic diseases of the nose and the paranasal sinuses are most common, frequently associated with bronchial asthma, and result in substantial reduction of quality of life. Despite optimal treatment according to guidelines, approx. $20 \%$ of the patients will report inadequate control of symptoms. Apart from well established surgical and conservative approaches in therapy new therapeutic antibodies are available that aim specifically pathophysiological targets. The optimal allocation of effective therapy for patients using appropriate biomarkers at the most suitable timepoint is the hallmark of stratified medicine and an important perspective in ENT.

\section{Inhaltsverzeichnis}

\section{Zusammenfassung}

Abstract

1. Biologicals und neue Behandlungsoptionen einer stratifizierten Medizin

1.1

1.2

1.3
Biologische medizinische Substanzen: eine Definition

Entwicklung und historische Meilensteine

rste Biologicals, hybride Moleküle und konzeptbedingte Vor- und Nachteile
1.4 Immunogenität $\quad$ S144

1.5 Anaphylaxien gegen Biologics: das Beispiel Cetuximab

1.6 Intendierte Immunologische Effekte und passagere Immunphänomene

$\begin{array}{llr}1.7 & \text { Biosimilars } & \text { S145 }\end{array}$
1.8 Small Molecules und DNAzyme $\quad$ S145

1.9 Kosten $\$ 145$

2. Rhinologie: Epidemiologie und Pathophysiologische Konzepte S146

2.1 Physiologie der Nasenschleimhaut und des integrierten

Schleimhautimmunsystems 


$\begin{array}{ll}\text { 2.2 } & \text { United Airways } \\ 2.3 \quad \text { Entitäten und Epidemiologie sinunasaler Erkrankungen } \\ \text { 2.3.2 } & \text { Tabakrauch } \\ \text { 2.3.3 } & \text { Allergien } \\ \text { 2.3.4 } & \text { Chronische Rhinitis } \\ \text { 2.3.5 } & \text { Chronische Rhinosinusitis } \\ \text { 2.4 } & \text { Endotypen chronischer Atemwegentzündungen } \\ \text { 2.5 } & \text { Stratifizierte, nachgelagerte Prävention } \\ \text { 3. } & \text { State of the art } \\ 4 . & \text { Biologika in Studien mit rhinologischen Erkrankungen } \\ 4.1 & \text { Allergische Rhinitis } \\ 4.1 .2 & \text { Studien mit VAK694 } \\ 4.2 & \text { Chronische Rhinosinusitis } \\ 4.2 .2 & \text { Reslizumab }\end{array}$

$\mathrm{S} 147$
$\mathrm{~S} 148$
$\mathrm{~S} 148$
$\mathrm{~S} 148$
$\mathrm{~S} 149$
$\mathrm{~S} 149$
$\mathrm{~S} 150$
$\mathrm{~S} 151$
$\mathrm{~S} 151$
$\mathrm{~S} 152$
$\mathrm{~S} 152$
$\mathrm{~S} 153$
$\mathrm{~S} 154$
$\mathrm{~S} 154$

$\begin{array}{ll}\text { 4.2.4 Benralizumab } & \mathrm{S} 155\end{array}$

$\begin{array}{ll}\text { 4.2.5 Dupilumab } & \$ 155\end{array}$

4.3 Beispiele für seltene Indikationen $\$$ S156

4.4 Biomarker $\$ 156$

4.4.1 Eosinophile im Vollblut und Gesamt-IgE: einfache inflammatorische Marker $\quad$ S156

4.4.2 Explorative Biomarker $\$$ S156

4.4.3 Molekulare Allergologie $\quad$ S156

5. Fazit und grundsätzliche Überlegungen zur
personalisierten Medizin

$\begin{array}{ll}\text { Literatur } & \mathbf{S 1 5 7}\end{array}$

\section{Biologicals und neue Behandlungsop- tionen einer stratifizierten Medizin}

Biologische Medikamente werden auf der Basis eines mechanistischen Verständnisses von Krankheitsprozessen hergestellt und bestehen in der Regel aus großmolekularen Stoffen, welche durch lebendige Organismen synthetisiert wurden und die selektiv über Bindung von Zytokinen oder Rezeptoren wirken [1]. Einleitend sollen daher zunächst die Entwicklung, eine kurze Systematik, biochemische Spezifika, immunologische Effekte und charakteristische Nebenwirkungen sowie aktuelle Trends dargestellt werden.

\subsection{Biologische medizinische Substanzen: eine Definition}

Die europäischen Zulassungsbehörden definieren Biologika (engl.: biologics oder biological medicinal products) als biopharmazeutische Arzneimittel, die als biologische medizinische Substanz in vivo und in der Regel therapeutisch eingesetzt werden. Hierzu gehören im weiteren Sinne biotechnologisch hergestellte aktive Substanzen, z. B. therapeutische Antikörper und rekombinante Proteine, aber auch Vaccinen und Allergene, Blut- und Plasmaprodukte sowie rekombinant hergestellten Alternativen [2]. Im lebenswissenschaftlichen und medizinischen Fachjargon hat sich der Begriff Biologics vornehmlich auf therapeutische Antikörper und seltener auch für rekombinante therapeutische Proteine etabliert.

\subsection{Entwicklung und historische Meilensteine}

Auf Basis mechanistischer Studien, molekularbiologischer und genetischer Grundlagenforschung wurden in den 1990er Jahren therapeutische Zielstrukturen definiert und sowohl in Tiermodellen als auch in humanen translationalen Modellen validiert, bevor sie klinisch erprobt wurden. Basierend auf einem von Milstein und Köhler (Nobelpreis für Medizin 1984) entwickelten Verfahren [3] können mittels immortalisierter, hybrider B-Zellen aus Myelomzellkulturen für eine fast beliebige Zielstruktur therapeutische Antikörper hergestellt werden. Durch weitere biotechnologische Verfahren wurden erstmalig neue Biopharmaka synthetisiert, geprüft und zugelassen, z. B. rekombinante Insuline (erste Zulassung durch FDA 1982) [4]. Regelrecht befeuert wurde diese Entwicklung durch die Transfusionsskandale der 1980er Jahre, akzidentelle Transmission von HIV oder HCV an Hämophiliepatienten und der Kontamination durch Creutzfeld-Jakob bei Hypophysenextrakten zur Wachstumshormonsubstitution. Auch rekombinante Gerinnungsfaktoren $[5,6]$ und Wachstumshormon (Zulassung durch FDA 1985) [7,8] wurden nun biotechnologisch hergestellt.

\subsection{Erste Biologicals, hybride Moleküle und konzeptbedingte Vor- und Nachteile}

Vor allem für onkologische und autoimmune Fragestellungen wurden vielversprechende monoklonale, neutralisierende Antikörper konstruiert, ferner Fusionsproteine mit Bindungskapazität (Etanercept), mit oder ohne intrinsische Aktivität (IL-4-Mutein), Rezeptorantagonisten, bi- und trispezifische Antikörper, die unterschiedliche Zielstrukturen binden können und gleichzeitig z. B. T-Zellen aktivieren. Rekombinante Zytokine sollten im damals dualen immunologischen Weltbild von Th1/Th2 Entzündungen $[9,10]$ die inflammatorische Balance wiederherstellen, z. B. durch Gabe von rekombinantem IL-12 Gabe bei Asthma [11], oder z. B. IL-10 [12] und IL-11 [13] bei Psoriasis. Anders als z. B. bei der Interferontherapie zur Behandlung Multipler Sklerose oder viraler Hepatitiden erreichten diese Studien ihre Zielpunkte nicht konsistent und zeigten teilweise relevante Nebenwirkungen. Daher wurden diese therapeutischen Ansätze nicht weiter verfolgt.

Neben der möglichen Vielfalt an biologisch potenziell einsetzbaren therapeutischen Proteinen wurde zugleich eine Vielzahl von biotechnologischen Expressionssystemen entwickelt [14]. Nach ersten prokaryotischen wurden sukkzessive eukaryotische Expressionssysteme entwickelt, die auch größere und glykosylierte Proteine mit komplexer Tertiär und Quartärstruktur in hoher und therapeutischer Qualität reproduzierbar zur Verfügung stellen konnten. Auch hinsichtlich der Optimierung der therapeutischen Antikörper auf Zielepitope und die Entwicklung der Extraktionsprozesse wurde viel Pionierarbeit geleistet [15-19].

Während ein biologisch aktives Humaninsulin ein Molekulargewicht von ca. 5000 Daltons aufweist, hat das Wachstumshormon 


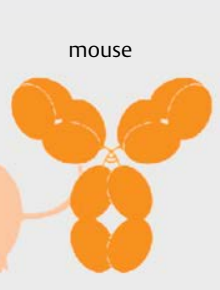

-omab

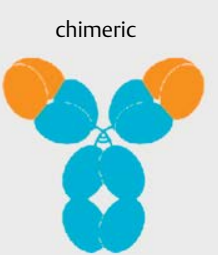

-ximab

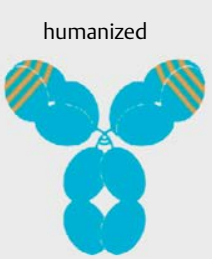

-zumab

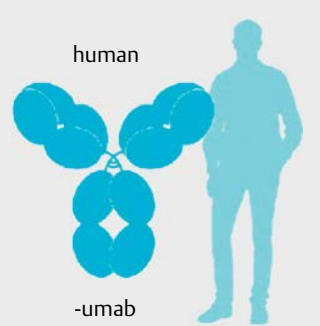

-umab

Major source designations until 2014

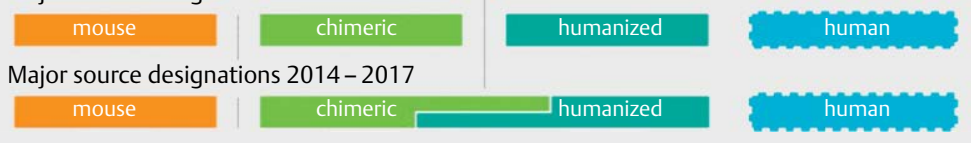

Abb. 1 Darstellung der internationalen, nichtproprietären Namen (INN) für die Entwicklung humanisierter und humaner Antikörper (Creative Common Lizenz, zitiert aus [21], Paul W.H.I. Parren et al. 2017, mABS).

Somatotropin ein Molekulargewicht von ca. 22000 Daltons [20]. Ein monoklonarer Antikörper liegt bei ca. 150000 Daltons, zum Vergleich: das Molekulargewicht von Acetylsalicylsäure liegt bei 180 Daltons. Die ersten therapeutischen Antikörper wurden als chimäre Proteine mit relativ hohen murinen oder anderen xenobiologischen Anteilen entwickelt und zunehmend humanisiert. Hieraus resultiert eine deutlich bessere Verträglichkeit, Wirksamkeit und Sicherheit für die Patienten. Diese Entwicklung ist auch in der Nomenklatur der Biologics abgebildet: so war der 1996 zugelassene in-vivo diagnostische anti-CEA-Antikörper Arcitumomab ein rein muriner Antikörper, der 1999 zugelassene therapeutische TNF- $\alpha$ Antikörper Infliximab ein chimärer Antikörper, der Herceptinantikörper Trastuzumab und der anti-IgE Antikörper Omalizumab humanisierte Antikörper, der TNF- $\alpha$ Antikörper Adalimumab ein vollständig humaner Antikörper (siehe auch $>$ Abb. 1) und [21].

\subsection{Immunogenität}

Neben einer intendierten immunologischen Wirkung besteht eine üblicherweise nicht gewollte immunologische Reaktion auf die biologisch aktiven und zumeist körperfremden Substanzen im Empfängerorganismus, welche als Immunogenität bezeichnet wird. Die murinen bzw. xenobiologischen Anteile einerseits und die Glykosylierungsmuster andererseits determinieren zu einem erheblichen Teil die Immunogenität der aktiven biologischen Substanz. Hieraus resultieren z. B. ADAs (engl.: anti-drug antibodies), die im besten Fall neutralisierend sind und zu einem Wirksamkeitsverlust führen, aber eben auch zu immunologischen Phänomenen wie Autoimmunhämolysen, Zytokinfreisetzungssyndromen, Mastzellaktivierung, Immunkomplex- und Serumerkrankungen führen können. Beispiele hierfür sind die verhältnismäßig hohen Raten an Reaktionen gegen Infliximab oder Rituximab, welche einen deutlichen murinen Anteil enthalten [22, 23]. Letztlich handelt es sich bei biologischen aktiven Substanzen um komplexe, große, biotechnologisch hergestellte Medikamente. Sowohl die Art der Herstellung, aber auch Kühlung, Licht, pH-Wert, Transport und Applikation können zu kleinen molekularen Veränderungen und hiermit zu Wirkungsverlust, Molekülaggregaten und gesteigerter Immunogenität führen. Ferner können kreuz- reagierende Epitope zu fatalen Anaphylaxien führen, v. a. wenn die Antigene auch IgE-Epitope sind, z. B. bei Cetuximab.

\subsection{Anaphylaxien gegen Biologics: das Beispiel Cetuximab}

Der EGF-Rezeptor Antikörper Cetuximab wurde 2003 in den USA (FDA) und 2004 in Europa (damals: EMEA) zunächst zur Behandlung des fortgeschrittenen Kolonkarzinoms zugelassen und wird seit Vorliegen pivotaler Studien zur Kombinationstherapie auch bei fortgeschrittenen Kopf-Hals-Karzinomen eingesetzt [24-26]. Bereits während der Zulassungsstudien in den frühen 2000er Jahren fielen in den USA regionale Unterschiede in der Inzidenz anaphylaktischer Reaktionen auf. So konnte zunächst 2007 O’Neil zeigen, dass bei Erstgabe die Wahrscheinlichkeit für eine anaphylaktische Reaktion global unter 3 \% lag. Im mittleren Südosten der USA jedoch, z. B. in Virginia, lag diese Rate bei bis zu 20\% [27, 28]. Diese Reaktion ist aber völlig anderer Natur als die vergleichsweise häufigen kutanen Reaktionen [29]. Platts-Mills und Kollegen konnten 2013 den Mechanismus der Sensibilisierung und die Assoziation zu Zeckenbissen und der Allergie gegen rotes Fleisch aufklären [30,31]. Die regionale Verbreitung einer Zeckenart, des sog. Lone-Star-Ticks führt nach Zeckenbiss zur Entwicklung galactose-alpha-1,3-galactose (alpha-GAL) spezifischer IgE Antikörper. Alpha-GAL ist ein bei allen nicht-primaten Säugetieren, Prosimianen und Neuweltaffen ein quasi ubiquitär exprimiertes Oligosaccharid der Glykoproteine der Zelloberfläche. Bei Primaten (Altweltaffen und Menschen) entsprechen ca. 1\% des zirkulierenden IgG-Pools alpha-GAL Antikörpern, und alpha-GAL ist ein wesentliches biologisches Hindernis einer einfachen Xenotransplantation [32]. Seit 2014 existieren kommerzielle Testsysteme, mittels denen spezifisches IgE gegen Alpha-GAL nachgewiesen werden kann. Der Ausschluss einer Sensibilisierung zur Vermeidung anaphylaktischer Reaktionen vor Gabe humanisierter Antikörper kann je nach Risikoprofil für die Patienten lebensrettend sein. Risikopatienten sind Menschen mit vielen Zeckenbissen, aus Forstberufen, Katzenallergie und dem Pork-Cat-Syndrom [33]. Die Bestimmung von alpha-GAL in diesem Risikokollektiv ist eine idealtypische Anwendung personalisierter Medizin gem. der WHO-Definition: Vermeidung von Nebenwirkungen durch spezifische Charakterisierung von Patienten. 


\subsection{Intendierte Immunologische Effekte und passagere Immunphänomene}

Die den meisten therapeutischen Antikörpern inhärente Wirkungsweise ist die Wirkung auf immunologische Prozesse, z. B. durch Antagonisierung bzw. Elimination von Botenstoffen der Entzündungskaskade (z. B. anti TNFa, anti IL-1, anti-IL-5) ( A Abb. 2).

Der Übergang von unerwünschten zu intendierten immunologischen Wirkungen ist fließend. Bi- oder sogar trispezifische Antikörper wie z. B. Catumaxomab, die bei fortgeschrittenen onkologischen Erkrankungen wie malignem Aszites eingesetzt werden und hierbei am Fc-Rezeptor einerseits, am aktivierenden T-Zellrezeptor CD3 und am epithelialen Zelladhäsionsmolekül EpCAM binden, aktivieren das Immunsystem gezielt und generieren durch die Zytokinfreisetzung neben der antineoplastischen Hauptwirkung eine inflammatorische Koaktivierung mit allerdings nicht unerheblichen Nebenwirkungen.

Ein weiterer intendierter Effekt ist die Inhibition regulatorischer immunologischer Prozesse auf T-Zellebene in vivo durch CheckPoint-Kinase Inhibitoren wie z. B. Inhibition von CTLA-4 durch Ipilimumab sowie Inhibition von PD-1 durch Nivolumab oder Pembrolizumab (Übersicht in: [34]).

In manchen Fällen werden durch Biologika hervorgerufene Autoimmunphänome bzw. Nebenwirkungen, wie z. B. bei Rituximab, durch die weitere kontinuierliche Gabe des gleichen Medikamentes de facto auf B-Zellebene kausal mittherapiert [35].

\subsection{Biosimilars}

Die Komplexität und Größe der Moleküle, die unterschiedlichen Expressionssysteme und Produktionsprozesse lassen echte Generika biologischer Medikamente selbst nach Ablauf des Patentschutzes nicht zu. Deswegen wurde das Konzept der Biosimilars geschaffen [36]. Ledford [37] bezeichnet Biosimilars als eine inexakte Kopie einer Referenzsubstanz. Die entscheidende Frage aus immunologischer Sicht lautet: wie ähnlich muss ein Biosimilar der Originalsubstanz sein? Die instrumentelle Definition der EMA bezeichnet ein Biosimilar hochgradig ähnlich einer Originatorsubstanz in allen wesentlichen Punkten, also Wirkungsmechanismus, Sicherheit, Herstellungsprozess. In der EU wird von den Herstellern von Biosimilars mind. eine klinische Studie gefordert, um die biologische Äquivalenz zu dokumentieren, welche auch eine weitgehende Austauschbarkeit des Biosimilars, die sog. switchability, mit der Originalsubstanz impliziert. Ferner müssen umfangreiche Immunogenitätsdaten und Herstellungsprozessdaten vorliegen. Hierbei ist wichtig, dass die Hersteller sich zu einer dauerhaften Pharmakovigilanz und umfangreichen Qualitätssicherung verpflichten. Wird die biologische Äquivalenz attestiert, darf das Biosimilar unter dem INN-Namen auf den Markt gebracht werden. Basierend auf der nun attestierten Äquivalenz können die Zulassungsbehörden eine Extrapolation zulassen, d. h. es wird aufgrund der vorliegenden Daten angenommen, dass das Biosimilar auch in allen anderen zugelassenen Indikationen äquivalent mit der Originatorsubstanz funktioniert [38, 39]. Die switchability und die Extrapolation sind die Punkte, die in der immunologischen Fachwelt besonders kontrovers diskutiert werden, da ein Großteil der Patienten mit Autoimmunerkrankungen diese Medikamente zusätzlich zu anderen immunmodulierenden Medikamenten erhält. Somit ist die Bewertung der Induktion von ADAs und der Austauschbarkeit besonders komplex. Auf Basis der aktuell den Zulassungsbehörden vorliegenden Daten ist allerdings von der Möglichkeit des Austausches resp. der switchability auszugehen [38]. Medikamente, die einer Originatorsubstanz stark ähneln, aber die diesen regulatorischen Prozess (z. B. in EU strukturiert durch die EMA, in USA durch die FDA) nicht durchlaufen, werden als intendierte Kopien bezeichnet. Diese Medikamente sind z. B. in Schwellenländern erhältlich und in der EU nicht zugelassen.

Biobetters sind Substanzen, die durch selektive kleine Änderungen veränderte physikochemische Eigenschaften, veränderte Bindungskapazitäten oder modifizierten Abbau resp. Clearance therapeutisch günstigere Eigenschaften erhalten. Ein Beispiel hierfür sind Insuline, die länger wirksam werden, oder pegylierte Antikörper, die durch die Bindung mit Polyethylenglykol (PEG) z. B. die Bioverfügbarkeit erhöhen [40].

\subsection{Small Molecules und DNAzyme}

Diese Medikamente sind ebenfalls durch ein rationales Design basierend auf mechanistischen Studien entstanden, aber entgegen gängiger Annahmen keine Biologics. Viele der small molecules agieren häufig als Tyrosinkinaseninhibitoren und setzen bestimmte genetische Subtypen oder Expression von Markern für eine erfolgreiche Therapie voraus und sind damit für eine präzise Medizin von außerordentlicher Bedeutung. Allerdings setzen sie aufgrund ihrer physikochemischen Eigenschaften völlig anders an und sind typische chemische Pharmaka, i.d.R. bis 800 Daltons Größe. Etabliert sind diese bei onkologischen Anwendungen. Aktivierende EGFR-Mutationen finden sich bei 10-15\% der Patienten mit Bronchialkarzinomen (z. B. Nichtraucher, Adenokarzinome) und sind daher für eine Therapie mit Gefitinib geeignet [41]. Inhibitoren der Januskinasen (sog. JAK-Inhibitoren), welche als zytoplasmatische Tyrosinkinasen die Aktivität von Zytokinrezeptoren vermitteln, können wie z. B. das small molecule Tofacitinib bei autoimmunen Erkrankungen [42] und auch möglicherweise als unterstützender Immunmodulator in der allergenspezifischen Immuntherapie eingesetzt werden [43]. Die Substanzen Ivacaftor und Lumacaftor sind als selektive Chloridkanalverstärker eine neue und vielversprechende Therapieoption bei Patienten mit zystischer Fibrose und einer delta F508 Mutation des CFTR-Gens und führen zu einer Reduktion pulmonaler Exazerbationen [44,45].

Ein topischer Effekt durch DNAzyme, die z. B. effektiv und spezifisch gegen den Th2-Transkriptionsfaktor GATA3 gerichtet sind und damit alle nachgelagerten immunpathologischen Th2 Reaktionen unterbinden [46], ist ebenfalls mechanistisch sehr elegant, aber definitionsgemäß kein Biologic.

\subsection{Kosten}

Der globale Markt für Biologics im Jahre 2020 wird auf 350 Milliarden Euro geschätzt [47]. Im Jahre 2016 wurden in Deutschland biologische Arzneimittel im Wert von ca. 6,4 Mrd. Euro innerhalb der GKV verordnet, entsprechend 19\% des Gesamtumsatzes aller Arzneimittel und 2,5\% aller Verordnungen [48]. Mögliche Kostensenkungen durch Biosimilars werden bei ca. $20-30 \%$ verortet, da die regulatorischen Hürden für die Zulassung und Pharmacovigilance sehr hoch liegen. Derzeit sind 28 Biosimilars in der EU zugelassen. Hierbei fällt auf, dass Kostensenkungen durch Wettberwerb v. a. dort möglich sind, wo mehrere Biosimilars zugelassen sind, wobei die Marktanteile der Biosimilars nicht notwendigerweise mit den Preisen korrelieren [49].

Nicht eingerechnet in diese Kalkulation ist allerdings die zunehmende Verordnungshäufigkeit, da sowohl die Fülle an neuen Molekülen, als auch zunehmende Anzahl von Indikationen und eine entsprechende 

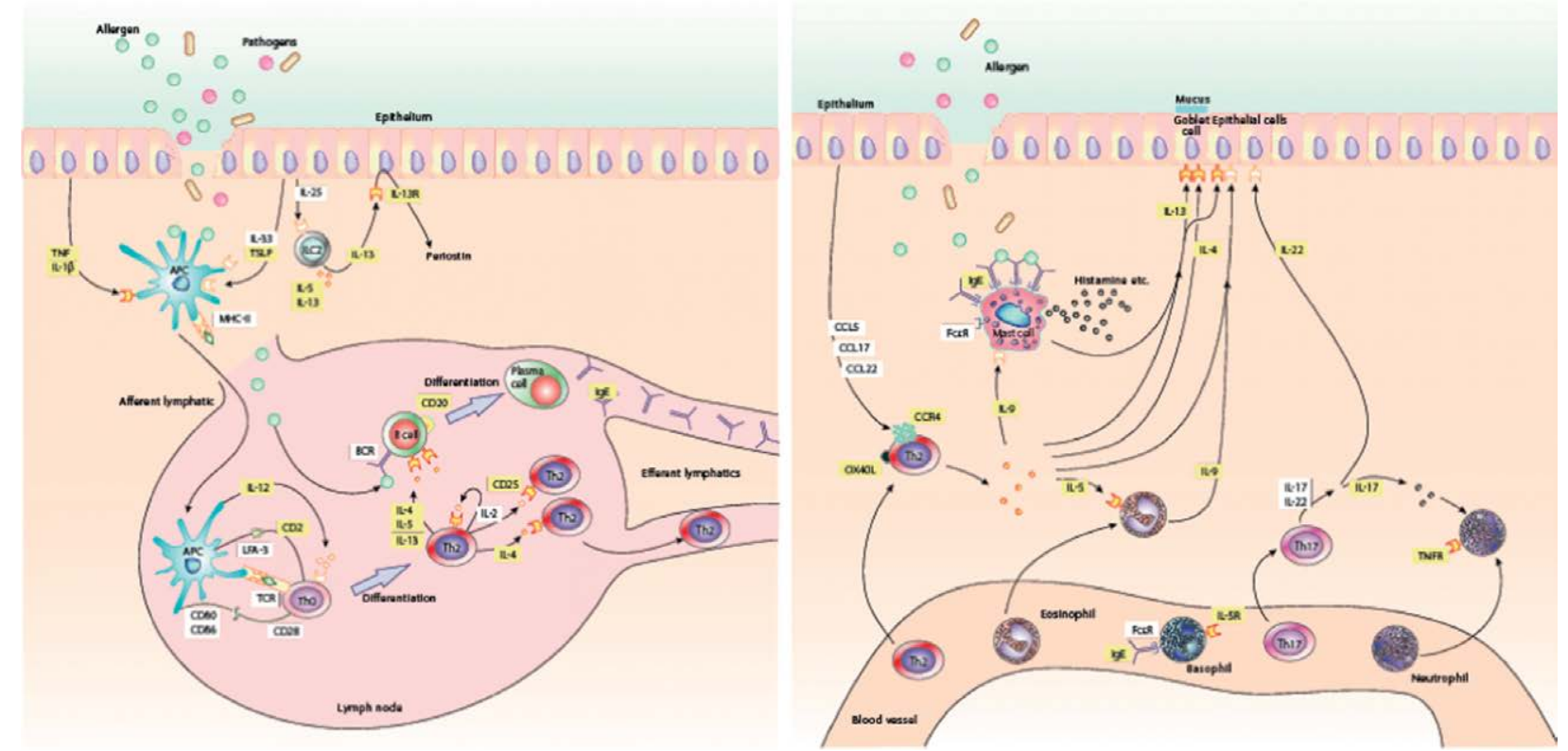

Abb. 2 Links dargestellt ist eine mukosale Immunreaktion gegen Allergene unter Einfluss weiterer Pathogene im Sinne einer Sensibilisierung. Hierbei sind Alarmine (IL-25, IL-33 und TSLP), proinflammatorische Zytokine (z. B. IL-4 IL-5, IL-13), antigenpräsentierende Zellen (APC), innate lymphoide Zellen (ILC) sowie T-Helferzellen und B-Zellen abgebildet. Rechts zeigt sich die Situation einer erneuten Exposition unter Involvierung von Mastzellen sowie einer zellulären Spätphasereaktion mit dem Influx von eosinophilen Granulozyten und T-Helferzellen unter Sekretion multipler Zytokine und der Nutzung interzellulärer Signalwege (nach [1], Boyman et al. Allergy 2015). Die mechanistische Charakterisierung dieser verschiedenen Entzündungswege ermöglicht eine zielgerichtete Therapie durch z. B. therapeutische Antikörper, sowohl für die Prozesse im Epithel als auch im subepithelialen Stroma (Lizenz durch RightsLink/John Wiley and Sons).

Marktdurchdringung zu beobachten ist. Für die EU und die USA rechnet IMS Health mit möglichen Einsparungen von 50 Mrd.- 100 Mrd. US\$ im Zeitraum von 2016-2020 durch den Einsatz von Biosimilars.

\section{Rhinologie: Epidemiologie und Pathophysiologische Konzepte}

Die Rhinologie betrifft die Lehre der Erkrankungen der äußeren und inneren Nase, der zugehörigen Nasennebenhöhlen sowie der Frontobasis und ihre chirurgische und konservative Therapie. Die Nase ist hierbei als Außenposten und Pforte der Atemwege ein Organ, welches ästhetische, funktionelle und immunologische Aufgaben übernimmt, als Sinnes-, Filter- und Reaktionsorgan [50].

\subsection{Physiologie der Nasenschleimhaut und des integrierten Schleimhautimmunsystems}

Die Nasenschleimhaut ist eine „first-line of defense“. Die Bewahrung der körperlichen Integrität durch die respiratorische Schleimhaut als aktive und passive Barriere, welche zugleich Ort für innate und adaptive Immunantworten ist, die komplexe Funktion der mukoziliären Clearance, die permanente Auseinandersetzung mit partikulären und löslichen Stoffen sowie Antigenen, Allergenen und Pathogenen resultieren in der uns HNO-Ärzten bekannten Nosologie und Pathologie [51]. Ein rationales Verständnis der inflammatorischen und protektiven Mechanismen hat zur Definition neuer therapeuti- scher Zielstrukturen und Konzepte geführt (siehe Übersichtsarbeit, HNO-Hauptreferat 2015 bei [52]).

Das in der Nase und den Nasennebenhöhlen in der regio respiratoria sowie partiell im Nasopharynx vorliegende respiratorische Epithel ist ein mehrreihiges Flimmerepithel, dessen Zilienfunktion dazu beiträgt, Mucus, mögliche schädliche inhalierte Substanzen und Partikel ostienwärts, respektive nach oral zu transportieren, wobei Pathologien des Zilienapparates fundamental die Atemwegsphysiologie alterieren [53]. Die Zilien übernehmen multiple Funktionen, u. a. konnte gezeigt werden, dass sie chemosensorisch sind. Zugleich ist das intakte respiratorische Epithel die Grundlage für funktionell intakte Abwehrfunktionen [54, 55]. An Stellen im Übergang zu verstärkter mechanischer Beanspruchung z. B. im Pharynx geht das Epithel in ein mehrschichtiges Plattenepithel über. Im Epithel finden sich Becherzellen, welche Mucine produzieren. Diese Mucine üben eine elementare Rolle in der unspezifischen mukosalen Immunität aus, beteiligen sich an der Barrierefunktion, interagieren antimikrobiell mit multiplen antimikrobiellen Peptiden und Defensinen [56], bilden ein hochflexibles und komplexes Mucin-Interactom aus [57] und wirken synergistisch mit inflammatorischen Zytokinen, z. B. IL-1 $\beta$ [58]. Submuköse Drüsen sezernieren zum einen das Nasensekret, welches eine transsudative („vasomotorische“) und sekretorische Komponente aufweist. Hierbei zeigen sich im luminalen Sekret Stoffe mit einer unspezifischen antimikrobiellen Aktivität wie z. B. Lysozym und Lactoferrin, Defensine sowie adaptive mukosale Antikörper vom IgA-Typ (IgA1 und IgA2) [59] und der Secretory-Component, 
welche die Biostabilität des sekretorischen IgA bedingt [60]. Ferner finden sich auch IgM und IgG. Das IgA wird durch Interaktion mit Kommensalen und äußeren Einflüssen induziert und kann zusätzlich sowohl Exotoxine als auch Pathogene neutralisieren, und durch transepithelialen Transport von slgA Kommensalen zurück nach luminal transportieren. Mukosales IgA erfüllt u. a. durch unterschiedliche Affinitäten multiple Funktionen der Immunexklusion [61], ist somit maßgeblich an der mukosalen Immunität der respiratorischen Schleimhaut beteiligt und determiniert einen aktiven antigenspezifischen Schutz an dieser wichtigen körperlichen Außengrenze der oberen Atemwege, welche bezogen auf die überzogene Fläche die am meisten exponierte Außenfläche des menschlichen Körpers ist.

Neben protektiven humoralen Mechanismen zeigt sich auch ein synergistisch agierendes zelluläres Kompartiment in der Schleimhaut der oberen Atemwege. Unspezifisch agieren neben Gewebemakrophagen v. a. je nach Stimuli und Pathologie eosinophile, neutrophile Granulozyten, Basophile und Mastzellen. Spezifisch und adaptiv wirken intraepitheliale Lymphozyten vom CD4 oder CD8 Typ, yठT-Zellen [62], innate lymphoide Zellen (ILC) [63] sowie NK-Zellen können zusammen mit submukösen lymphozytären Infiltraten der Lamina propria und speziellen, funktionell angepassten NALT-Regionen mit adaptierten M-Zellen und Domarealen sowohl tolerogene, allergische als auch zytotoxische Immunantworten auslösen [64, 65]. Weiterhin besteht als Bestandteil des integrierten mukosalen Schleimhautsystems im Nasopharynx die Tonsilla pharyngea, welche in der Regel mit dem Schulkindalter involutiert. Neben T-Zellinfiltraten bei z. B. allergischer Rhinitis und chronischer Rhinosinusitis mit Nasenpolypen existieren auch Areale einer lokalen lgE-Produktion durch B-Zellen [66], sowie dendritische Zellen [67,68]. Diese professionellen antigenpräsentierenden, teilweise immaturen CD1 + CD11 + Zellen bilden gemeinsam mit makrophagenähnlichen dendritischen CD11 + CD14 + CD68 + Zellen ein dichtes Netz zur Regulation adaptiver Immunantworten [69] und exprimieren v. a. bei Atopikern den hochaffinen IgE-Rezeptor FcعRI sowie costimulatorische Moleküle wie CD80, CD86 und CD40 [70]. Es ist davon auszugehen, dass, auch abseits lymphoepithelialer Bezirke, das respiratorische Epithel sich funktionell an bestehende immunologische Verhältnisse adaptiert. Hierbei wird es zum einen durch inflammatorische Stimuli wie z. B. IFNy oder IL-4 in seinem Transkriptom und konsekutiv funktionellen Eigenschaften verändert. Dieses führt z. B. über eine Reduktion der Expression von Tight Junction Proteinen in der Folge zu einer defekten Barrierefunktion [71]. Allerdings ist das Epithel als ein Immunointerface auch an Initiierung und Aufrechterhaltung z.B. allergischer Entzündungen mittels inflammatorischer Zytokine wie TSLP [72], IL-25 [73] oder IL-24 [74] aktiv involviert. Auch die Induktion von epithelialen Alarminen wie IL-33 trägt zur Induktion mukosaler Inflammation bei [75]. Im Vollbild einer chronischen Rhinosinusitis mit Nasenpolypen westlicher Prägung finden wir prädominierend eine Typ2-Entzündung mit eosinophilen Infiltraten, lokaler Expression von IL-5, IL-13 und der Präsenz von IgE [76-78] (siehe auch unter 2.4: Endotypen und Übersicht bei [52]).

\subsection{United Airways}

Die funktionelle und physiologische Verbindung der oberen mit den unteren Atemwegen wird uns HNO-Ärzten bei der Behandlung unserer Patienten täglich bewusst, die Assoziation v. a. klinisch schwe- rer Verläufe z. B. einer chronischen Sinusitis mit chronischer Bronchitis und Asthma oder allergischer Rhinitis und Asthma ist sowohl aus der Praxis als auch der Epidemiologie zu ersehen.

In einer prospektiven longitudinalen Populationskohorte aus Dänemark wurde 2002 der Zusammenhang erstmalig zwischen allergischer Rhinitis und allergischem Asthma bei Pollenallergikern überzeugend dokumentiert [79]. Vorherige Studien, auch aus gut strukturierten nationalen Kohorten [80] konnten zwar Assoziationen zeigen, nutzten aber nicht-adjustierte Datensätze.

2008 konnten Shaaban und Kollegen [81] aus einer europäischen longitudinalen Kohortenstudie in 14 europäischen Ländern bei über 6460 Patienten zeigen, dass im Beobachtungszeitraum von knapp 9 Jahren bei Patienten mit allergischer Rhinitis ein ca. 4-fach erhöhtes Risiko besteht, an Asthma bronchiale zu erkranken. Das adjustierte relative Risiko lag bei 3,53 (95\% Cl 2,11-5.91) für allergische Rhinitis und, auch das ist ein relevantes Ergebnis, bei 2,71 (95\% Cl 1,644.46) für nicht-allergische Rhinitis.

Auch bei chronischer Rhinosinusitis ist die Assoziation zu Asthma epidemiologisch [82] und mechanistisch abseits der typischen Vidaloder Samter-Trias, untersucht worden. Je nach Stichprobe liegt der Anteil asthmatischer Patienten im Krankheitskollektiv mit CRS zwischen 25-70\% [83, 84]. Eine britische Arbeitsgruppe untersuchte eine klinische Kohorte mit 57 Patienten mit CRSwNP in Bezug auf Lungenfunktion, bronchiale Hyperreaktivität und exhaliertes Stickstoffmonoxid (FeNO). Hierbei konnte u. a. gezeigt werden, dass 3 klinische Gruppen mit unterschiedlichen Phänotypen charakterisiert werden konnten, die sich allerdings nicht in den Schweregraden ihrer sinunasalen Beschwerden unterschieden [85]. Nicht nur bei allergischem Asthma, sondern auch bei nicht-allergischem Asthma und bei COPD ließen sich assoziierte sinunasale Pathologien zeigen: Patienten mit nicht-allergischem Asthma und COPD zeigen eine höhere Symptomlast im validierten SNOT-20 Fragebogen, sowie erhöhte Konzentrationen inflammatorischer Zytokine im Nasensekret, z. B. IFNy und G-CSF, aber auch Eotaxin und MCP-1 [86].

Das didaktisch und funktionell interessante Konzept des „atopic march“ [87] passt in ein solches letztlich am ehesten T-Zellvermitteltes Konzept, welches die Migration antigenspezifischer, inflammatorischer T-Zellen postuliert.

Braunstahl führte in den frühen 2000er Jahren segmental-bronchiale und nasale Allergenprovokationen durch, und konnte zeigen, dass eine segmentale, bronchiale Allergenprovokation zu einer Infiltration IL-5 produzierender Zellen und von Eosinophilen in die Nasenschleimhaut führte [88]. Eine nasale Allergenprovokation führte wiederum zu einer gesteigerten Expression von epithelialen (ICAM1) und vaskulären (VCAM-1) Adhäsionsmolekülen in der Bronchialschleimhaut, die mit der Anzahl lokal exprimierter Eosinophilen korrelierte [89]. Auch Infiltrate mit Basophilen und Mastzellen konnten gezeigt werden [90]. Bei aller Eleganz des Studiendesigns ist die Hauptschwäche dieser Studien, dass die zelluläre Quelle des pro-eosinophil wirkenden IL-5 weder immunhistologisch noch funktionell determiniert wurde.

Die Interaktionen zwischen oberen und unteren Atemwegen sind bei weitem nicht nur immunologischer Natur: so konnte die Arbeitsgruppe um Baroody und Naclerio zeigen, dass die Nasenschleimhaut von Patienten mit allergischem Asthma die Atemluft schlechter konditionieren, d. h. erwärmen und befeuchten kann [91, 92]. 


\subsection{Entitäten und Epidemiologie sinunasaler Erkrankungen}

\subsubsection{Infektionen}

Die häufigste Ursache sinunasaler Erkrankungen sind akute virale Infekte mit respiratorischen Viren, primär bakterielle Rhinosinusitiden sind vergleichsweise selten. Die Ätiologie chronischer Rhinitiden und der chronischen Rhinosinusitis ist komplex und ob im Sinne einer „first hit hypothese“ am Anfang der entzündlichen Kaskade virale, fungale oder bakterielle Infektionen stehen, ist weitestgehend unklar. Auch die Rolle von Allergien, seien sie lokaler oder systemischer Natur ist nicht final geklärt.

Der „banale“ virale Schnupfen, Coryza, ist de facto die häufigste Infektionserkrankung überhaupt, wird wegen der schweren Abgrenzbarkeit von Eccles mehr als kulturelles Konzept denn als definierte klinische Entität bewertet [93]. Die 99 Serotypen der humanen Rhinoviren wurden inzwischen phylogenetisch untersucht [94] und vollständig sequenziert [95]. Die Variabilität dieser Viren ist sehr hoch und für das Immunsystem daher diffizil: neben der Vielfalt an Antigenen und der spezifischen Virulenz der Erreger sind es auch die Erreger-Wirt Interaktionen, welche Pathogenität und Penetranz determinieren. Ein Beispiel ist die genetische Assoziation von bronchialen Rhinovirusinfektionen und kindlichem Asthma [96].

Ein Th2-Mikromilieu führt in vitro unter Einfluss des Zytokins IL-13 über Heraufregulation des epithelialen Adhäsionsfaktors ICAM-1 zu einer erhöhten Infektionsrate mit humanen Rhinoviren [97]. Dieser vermeintlich einfache Zusammenhang blieb in Kohorten bisher unbestätigt. Allerdings konnte gezeigt werden, dass Kinder mit Asthma eine deutlich länger andauernde postvirale Hyperreagibilität der Atemwege aufweisen [98]. Aus einer afebrilen Rhinovirusinfektion kann eine Exazerbation einer chronischen Rhinosinusitis oder ein exazerbiertes Asthma entstehen [99, 100]. Rhinoviren sind vermutlich für ca. 50\% der respiratorischen Infekte verantwortlich, neben Influenza, Adenoviren, Coronaviren und RSV (Respiratory Syncitial Virus). Vor allem Influenzaviren sind für Vaccinierungsstrategien zugänglich [101].

Die frühe Infektion mit RSV wird auch als Risikofaktor für die Entwicklung eines allergischen Asthma gesehen [102,103]. Entwicklungen von Vaccinierungsstrategien für Coronaviren und RSV sind v. a. für Risikopopulationen im Sinne einer stratifizierten Prävention von Bedeutung. Zur Prophylaxe von RSV-Pneumonien bei suszeptiblen Kindern (z. B. Frühgeborene) steht mit dem Biologic Pavilizumab ein sekundärpräventiv einzusetzender, passiv immunisierender Antikörper zur Verfügung (Guideline in Pediatrics: [104]).

Die Rolle viraler Infekte der oberen Atemwege auf Genese und Exazerbation ist bisher nur unzureichend verstanden, in vitro Modelle zeigen v. a. eine Induktion costimulatorischer Signale [105] im Epithel und z. B. die synergistische Einwirkung im Th2-Mikromilieu auf Pendrine, welche u. a. zur Dyskrinie und Sekretion bei chronischer Rhinosinusitis beitragen [106].

Akut bakterielle Superinfektionen einer viralen Sinusitis treten in ca. $2 \%$ der unkomplizierten Fälle auf [107-109]. Die häufigsten Keime bei einfacher akuter bakterieller Rhinosinusitis ohne vorbestehende chronische Rhinosinusitis sind Streptoccocus pneumoniae, Haemophilus influenzae, Moraxella catarrhalis und Staphylococcus aureus. Bei vorbestehender Infektion mit Rhinoviren konnte eine erhöhte Adhäsion verschiedener Bakterien, u. a. für S. aureus gezeigt werden [110].
Bei Atopikern liegt unter dem Einfluss von IL-4 eine alterierte Funktion der granulozytären Abwehr [111] vor, im Modell sind daher bakterielle Superinfektionen mechanistisch gut erklärbar. Dabei sind die mikrobiellen Interaktionen bei chronischer Rhinosinusitis komplexer Natur. Zum einen spielen Biofilme eine relevante Rolle [112], ferner ist das Mikrobiom im untersuchten Krankheitskollektiv wahrscheinlich iatrogen alteriert und in seiner Diversität stark zu Gunsten einzelner Spezies eingeschränkt. So zeigten Abreu und Kollegen einen Verlust von Milchsäurebakterien zu Gunsten von Corynebacterium tuberculostearium [113]. Choi und Kollegen konnten eine Besiedlung mit S. aureus identifizieren [114]. Da v. a. schwere Fälle einer CRS mit Nasenpolypen mit der Präsenz von spezifischem lgE gegen S. aureus Enterotoxin vergesellschaftet sind, und auch die Kolonialisation der Mukosa mit S. aureus mit Nasenpolypen, einer Gewebeeosinophilie und einem Th2-Mikromilieu assoziiert ist [115], stellt sich die Frage nach Ursache und Wirkung. Tatsächlich findet sich S. aureus IgE auch im schweren Erwachsenenasthma [116] und die Involvierung von Superantigenen im atopischen Ekzem ist sowohl klinisch als auch experimentell dokumentiert [117]. Die Rolle eines komplexen Mikrobioms ist in diesen heterogenen und häufig mit Antibiotika vorbehandelten Kollektiven daher nur schwer abschätzbar. Daten zur Exazerbation durch bakterielle Superinfektion bei CRS sind lückenhaft. Therapeutische Mikrobiominterventionen, z. B. als Mikrobiotatransfer sind ein vielversprechendes Instrument der personalisierten Medizin [118], allerdings in der Rhinologie bisher nicht publiziert.

\subsubsection{Tabakrauch}

Tabakrauch konnte konsistent als unabhängiger Risikofaktor für Sinusitis in epidemiologischen Studien gezeigt werden (OR 1,7: $95 \%$ CI 1,6-1,9) [119], Übersicht im HNO-Referat von Beule [120].

\subsubsection{Allergien}

Weltweit sind zwischen 10-40\% aller Menschen von einer allergischen Rhinitis betroffen [121, 122]. Zur Untersuchung der Epidemiologie der allergischen Rhinitis gibt es seit Jahren konsistent strukturierte, internationale Krankheitskohorten, überwiegend im Standard von ISAAC (International Study of Asthma and Allergy in Childhood [123]), die zudem von populationsbasierten, repräsentativen Kohortenstudien gestützt werden. Uni sono ergibt sich seit den 1980er Jahren ein Bild der global ansteigenden, in letzter Zeit zumindest in Europa leicht stagnierenden, Prävalenz respiratorischer Allergien. Ca. 500 Millionen Menschen leiden wahrscheinlich weltweit an allergischer Rhinitis, die sozioökonomischen Folgen sind erheblich (Übersicht in [122]). In Deutschland zeigen die Daten der Studie zur Gesundheit Erwachsener (DEGS1) eine Lebenszeitprävalenz für allergische Erkrankungen von ca. 30\% [124]. Im Rahmen einer bevölkerungsbezogenen Stichprobe mit mehr als 7000 Blutproben von Erwachsenen wiesen mind. 48\% der Patienten eine allergische Sensibilisierung auf, hierbei waren insgesamt 33,6\% der Teilnehmer gegen Aeroallergene sensibilisiert [125]. Diese Zahlen wurden durch das Robert Koch Institut (RKI) in der mit über 23000 zufällig ausgewählten Personen allgemeinen Studie „Gesundheit Erwachsener in Deutschland 2014“ (GEDA-Studie) bestätigt, das RKI spricht von einem „Allergie-Tsunami“: die 12-Monatsprävalenz für allergische Erkrankungen lag bei rund $28 \%$ [126]. In den USA sind ebenfalls bis zu 30 \% der Bevölkerung an einer allergischen Rhinitis erkrankt, ca. 
60 \% können ihre Symptome durch Therapie mit Antihistaminika oder topischen Steroiden nicht adäquat kontrollieren [127]. In Deutschland werden nur ca. $10 \%$ der Patienten leitliniengerecht behandelt [128]. Die einzige kausale therapeutische Option zur Behandlung der allergischen Rhinitis ist die spezifische Immuntherapie $[122,129]$, diese zeigt eine hervorragend dokumentierte klinische Wirksamkeit und Sicherheit, sowohl als subkutane [130] als auch sublinguale Immuntherapie [131-133] und wirkt nachgelagert präventiv auf die Entwicklung eines allergischen Asthma bronchiale [134-136] (siehe auch 2.5).

\subsubsection{Chronische Rhinitis}

Verhältnismäßig gute epidemiologische Daten zur chronischen Rhinitis bei Adoleszenten finden sich durch die Isle of Wight Geburtskohorte, die auch die Assoziation verschiedener Cluster zum Asthmarisiko darstellt [137]. Die chronische Rhinitis als Differentialdiagnose zur chronischen Rhinosinusitis abzugrenzen ist klinisch und begrifflich nicht trivial, aktuelle Darstellungen definieren den fachlichen Konsensus, robuste Daten sind im Vergleich zur allergischen Rhinitis nicht verfügbar [138, 139]. Bei der nicht-allergischen chronischen Rhinitis existieren mit der Nicht-Allergischen Rhinitis mit Eosinophilie (NARES) [140], der hormonellen Rhinopathie, einer Rhinitis mit neurogener Inflammation [141] (die ggf. ein eigener Endotyp ist, s.u. 2.4) und der idiopathischen Rhinitis (im angelsächsischen weiterhin häufig als vasomotorische Rhinitis bezeichnet) Subtypen, die selektiv pharmakologisch mit topisch nasalen Steroiden, einer topischen Parasympathikolyse mitz. B. Ipratropiumbromid (off-label in Deutschland) oder Capsaicin (sofern verfügbar) behandelbar sind.

\subsubsection{Chronische Rhinosinusitis}

Der Kategorialbegriff der chronischen Rhinosinusitis bezeichnet entzündliche Erkrankungen der Nase und der Nasennebenhöhlen mit einer Krankheitsdauer von über 12 Wochen. Die EPOS3-Leitlinie von 2012 [107] definiert chronische Rhinosinusitis als mind. 12 Wochen andauernde Erkrankung der Nase und ihrer Nebenhöhlen, charakterisiert mit mehr als 2 der folgenden Symptome: a. Nasenatmungsbehinderung b. Rhinorrhoe c. Druckgefühl oder Schmerzen im Gesicht d. Hyp-oder Anosmie, wobei entweder mind. Nasenatmungsbehinderung oder Rhinorrhoe als obligate Symptome vorliegen sollen. Klinisch sollen entweder endoskopische Zeichen von Nasenpolypen, eine mukopurulente Rhinorrhoe aus dem mittleren Nasengang und/oder CT-morphologische Zeichen von Schleimhautveränderungen in der ostiomeatalen Einheit oder der Nasennebenhöhlen vorliegen. Diese Definition aus dem europäischen Positionspapier wurde in den letzten Jahren zunehmend international akzeptiert. Ebenfalls wurde, unabhängig der Ätiologie und Pathogenese der Erkrankung die chronische Rhinosinusitis in eine mit (english: with) Nasenpolypen (CRSwNP) und eine chronische Rhinosinusitis ohne (lat. sine) CRSsNP unterteilt [107, 142].

Die Epidemiologie der chronischen Rhinosinusitis methodisch und regional konsistent zu untersuchen ist schwierig. Zum einen bestehen bei identischen Erhebungsmethoden deutliche regionale Unterschiede, zum anderen bestehen sehr unterschiedliche Ansätze zur Erhebung, bspw. durch ärztliche Diagnose und, inzwischen allgemein in der epidemiologischen Methodik etabliert, durch Fragebogensysteme und/oder der Erfassung der krankheitsbezogenen Lebensqualität. Eine umfassende Übersicht findet sich bei [120]. Die konsistentesten Erhebungen mittels standardisierter Fragebögen im Rahmen des „Global Allergy and Asthma Network of Excellence“ (GA2LEN) wurden singulär für chronische Rhinosinusitis [119] und kombiniert für Asthma in Assoziation mit chronischer Rhinosinusitis durchgeführt [82].

Hierbei konnte erstere Studie bei über 57000 Rückmeldungen aus 12 verschiedenen europäischen Ländern mit Patienten im Alter zwischen 15-75 Jahren eine globale Prävalenz von 10,9\% (Intervall 6,9-27,1\%) gemäß der Definition der europäischen Leitlinien feststellen. Diese Daten wurden u. a. in einer amerikanischen Studie mit einer globalen Prävalenz der CRS von 11,9\% [143] bestätigt. Die zweite Studie [82] untersuchte in diesem Datensatz zusätzlich die Assoziation zu Asthma. Trotz der Heterogenität in der Prävalenz der CRS zwischen den einzelnen Regionen in Europa war die Assoziation zwischen CRS und Asthma über alle Zentren und Altersgruppen vergleichbar (adjustierte OR: 3,47; 95\% Cl: 3,20-3,76). Patienten, die zusätzlich zu den Symptomen ihrer CRS eine allergische Rhinitis angaben, hatten ein nochmals deutlich erhöhtes Risiko, von einem Asthma betroffen zu sein (adjustierte OR: 11,85; $95 \% \mathrm{Cl}$ : 10,5713,17). Bei Nichtallergikern hingegen zeigte sich eine Assoziation zu einem sog. late-onset Asthma. CRS geht einher mit einer deutlich reduzierten Lebensqualität und hat eine hohe sozioökonomische Bedeutung [144].

Die Analgetikaintoleranz, welche im angelsächsischen Schrifttum als AERD, aspirin exacerbated respiratory disease bezeichnet wird, ist eher mit schweren Verläufen assoziiert [107]. Eine aktuelle Metaanalyse [145] berichtete eine 7-15\% Prävalenz der AERD bei Asthmatikern und eine erhöhte Prävalenz bei schweren Fällen. Patienten mit einer CRS zeigten in rund 8,7\% der Fälle, Patienten mit einer gesicherten CRSwNP in rund 9,7\% die Symptome einer AERD. Gem. [107] EPOS3 zeigten ca. 15\% der Patienten mit einer CRS eine AERD. Zhang und Kollegen konnten zeigen, dass spezifisches IgE gegen S. aureus Enterotoxin bei diesen Patienten überproportional häufig exprimiert ist [146].

Wichtige, jedoch auch deutlich seltenere Differentialdiagnosen stellen autoimmune Systemerkrankungen mit sinunasaler Beteiligung dar. Hier sind v. a. Vaskulitiden zu nennen, deren klinische Bilder stadienabhängig z. T. erheblich einer chronischen Rhinosinusitis ähneln können [147, 148]. Hier wurden zuletzt an der Nomenklatur des American College of Rheumatolology (ACR) Änderungen vorgenommen, v. a. sind an dieser Stelle GPA (vormalig Wegener'sche Granulomatose [149]) und die eosinophile Granulomatose mit Polyangitis (vormalig Churg-Strauss Vaskulitis) zu nennen. Die Kriterien zur Diagnosestellung der GPA der Europäischen Liga Rheumatologie (EULAR) und dem ACR sind aufgrund der aktuellen „Diagnostic and Classification Criteria in Vasculitis Study“ (DCVAS)-Studie derzeit in Revision [150]. Für eine Therapie der GPA mit Rituximab wird inzwischen der Empfehlungsgrad A ausgesprochen [151]. Mechanistisch ist außerdem die eosinophile GPA ein interessantes Target für Antikörper, die sich gegen IL-5 oder seinen Rezeptor richten und auch schon in klinischen Studien untersucht wurden ([152], 4.2 s.u.).

Die zystische Fibrose (auch Mukoviszidose) ist die häufigste autosomal-rezessiv vererbte genetische Erkrankung (1: 2000 Lebendgeburten) und geht mit einer Fehlfunktion von membranalen Chloridkanälen, dem CFTR (Cystic Fibrosis Transmembrane Regulator) einher, die in den Atemwegen sowie im Gastrointestinaltrakt in einer veränderten Mucuszusammensetzung resultiert. In den Atemwe- 
gen führt der zähe, nur erschwert mobilisierbare Schleim zu rekurrenten, opportunistischen und häufig lebensbedrohlichen bronchopulmonalen und sinunasalen Infektionen. Die alterierte Funktion im Gastrointestinaltrakt bedingt bei fehlender Enzymsubstitution aufgrund einer exokrinen Pankreasinsuffizienz malnutritive Syndrome. Beinahe 2000 Mutationen des CFTR-Gens sind bekannt, daher variieren die Phänotypen teils deutlich (Übersicht bei $[44,45]$ ). Bei mind. 25-40\% aller Patienten findet sich eine sinunasale Polyposis $[107,153]$. Phänotypisch existieren je nach Stichprobe histologische Subtypen mit eher neutrophilen oder eosinophilen Entzündungsmustern ([154, 155]. Bei der Therapie der CF haben sich neue selektive Therapien mit small molecules etabliert (s. o. 1.8).

Das sehr viel seltenere Kartagenersyndrom [156] ist der Prototyp einer Ziliendyskinesie [53] und geht obligat mit einer sinunasalen Polyposis, zudem Bronchiektasen und einem Situs inversus einher. Die Polypen können ebenfalls eosinophile Infiltrate aufweisen, interessanterweise wurde zudem eine deutlich reduzierte Expression der NO-Synthethase im Gewebe demonstriert [157]. Dieser Befund passt a priori zu niedrigen exhalierten NO-Werten in der Diagnostik [158]. Die Nutzung einer eNose kann in Exhalaten zwischen gesunden Patienten, Kartagenersyndrom und zystischer Fibrose mit respektive ohne chronische Infektion mit Pseudomonas aeroginosa unterscheiden [159] und ist hierdurch ein interessantes neues Werkzeug zur möglichen Endotypisierung.

\subsection{Endotypen chronischer Atemwegentzündungen}

Die phänotypische Definition der Erkrankung einer chronischen Sinusitis mit oder ohne Nasenpolypen sagt zunächst nichts über ihren molekularen Entstehungsmechanismus aus, kann den Therapieerfolg nicht voraussagen und hilft auch nicht bei der Allokation der optimalen Therapie, also z. B. konservative Standardtherapie mit oder ohne Operation [142,160]. Ein profundes mechanistisches Verständnis ist allerdings die Grundlage für eine gezielte, idealerweise präzise und personalisierte Therapie. Die hypothesenbasierte immunologische Entzündungsforschung der letzten 30 Jahre hat vornehmlich auf Basis des auch didaktisch eleganten Th1/Th2 Modells [9, 10] die Assoziation von allergischen Atemwegserkrankungen mit einer phänotypischen prädominanten Eosinophilie zu den Th2 Erkrankungen identifiziert. Dieses wurde erstmalig durch Bachert [76] für die chronische Sinusitis mit Nasenpolypen gezeigt, weitere intensivierte Untersuchungen von Zytokinmustern [77] und auch der involvierten T-Zellklone [161] folgten. Allerdings entdeckte man z. B. in asiatischen Kohorten ein anderes Entzündungsmuster mit überwiegend IL-17 assoziierten Entzündungsmustern [162]. Die mukosalen Entzündungsmuster scheinen dabei einem mechanistischen, und ursächlich wahrscheinlich soziokulturellen Wandel [163], hin zu einem „westlicheren“ Zytokinprofil, zu unterliegen. Des Weiteren wurden in Zentralchina Patienten mit CRSwNP diagnostiziert, bei denen keines der klassischen Zytokinmikromilieus, also weder eine Th1 noch Th2 noch Th17 Entzündung überwog [164]. Auch Sonderformen der CRS, z. B. bei zystischer Fibrose, finden sich andere Entzündungssignaturen [161, 165]. Das Vorhandensein unterschiedlicher Infiltrate korreliert auch mit dem Ansprechen auf Therapie. So konnte Wen [166] zeigen, dass Nasenpolypen mit überwiegend neutrophilen Infiltraten klinisch nicht auf orale Steroidbehandlung ansprechen. Mucin-1 Expression konnte hingegen als Marker für ein Ansprechen auf Steroide identifiziert werden [167].
Die in den westlichen Industrieländern dominierende Th2-assoziierte Pathophysiologie bei entzündlichen Atemwegserkrankungen hat zu entsprechenden biomedizinischen Therapiekonzepten geführt, welche ganz überwiegend Zytokine aus dem Th2-Mikromilieu adressieren (siehe 4.2, klinische Studien). Abseits der Frage nach Bezahlbarkeit neuer Therapieverfahren hat sich im Rahmen der personalisierten Medizin ein Konzept etabliert, welches Endotypen beschreibt. Erstmalig von Anderson [168] beschrieben, sollte dieses Konzept zu einem selektiveren und mechanistisch rationalen therapeutischen Vorgehen führen. Bei der Definition von Endotypen werden z. B. genetische, mechanistische, histologische oder funktionelle Charakteristika gruppiert, um unterschiedliche und mechanistisch kohärente Entitäten zu definieren [169]. Wenzel beschrieb vereinfacht einen „Molekularen Phänotyp“ [170]. Zwar befassten sich in den letzten Jahren mehrere Positionspapiere sehr namhafter Autoren mit diesem Konzept: immerhin, und das ist ein großer Fortschritt, ist für die chronische Rhinosinusitis eine europäische, multizentrische Analyse und rein datengetriebene Studie verfügbar [171].

Für diese Kohorte im GA2LEN Netzwerk wurden initial $917 \mathrm{~Pa}$ tienten in 8 europäischen Ländern resp. 10 europäischen Universtitätskliniken rekrutiert. Von 173 Patienten mit CRS und 89 Kontrollen konnte letztlich in adäquater Qualität und Menge Gewebe zur Analyse gewonnen werden. Hierbei wurden anhand einer vordefinierten Biomarkerauswahl sämtliche Proben charakterisiert und durch eine hypothesenfreie Analyse zu 10 verschiedenen Gruppen zugeordnet. Es wurden entzündliche Parameter (MPO, IL-1 $\beta$, IL-6 und IL-8), Typ2-Entzündungsmarker (IgE, ECP, IL-5 und Albumin), in der 3. Gruppe IL-17, TNF- $\alpha$ und IL-22, und ferner in 2 weiteren Gruppen IFNy, TGF $\beta_{1}$, S. aureus enterotoxin IgE im Rahmen einer hierarchischen Clusteranalyse untersucht. Die resultierenden 10 Cluster wurden dann mit klinischen Phänotypen verglichen und erschienen sowohl mechanistisch als auch klinisch plausible und kohärente Subtypen abzubilden. So zeigten die IL-5 negativen Gruppen klinisch überwiegend eine chronische Rhinosinusitis ohne Nasenpolypen und ohne Asthma, während die IL-5 positiven Gruppen, welche auch hohe systemische und lokale IgE-Level aufwiesen, mit einem hohen Anteil an Asthma erkrankten Patienten einhergingen. Die Patienten, die besonders hohe IgE-Werte sowie spezifisches IgE gegen S. aureus Enterotoxin zeigten, litten durchweg an chronischer Rhinosinusitis mit Nasenpolypen und fast alle an comorbidem Asthma bronchiale. Die Studie hat leider einen relevanten Schwachpunkt: Sie hat, obwohl mit Sicherheit erhoben, keine weiteren klinischen Daten mit abgebildet, also standardisierte Symptomscores und/oder krankheitsbezogene Lebensqualität. Idealerweise hätten auch mehr der initial über 900 Patienten in die Analyse eingeschlossen werden können und sollen, dennoch möchte man vorsichtig 3 grundlegende, z. B. in Versorgungsdaten und weiteren klinischen Studien zu überprüfende axiomatische Aussagen treffen:

1. Je kranker ein Patient mit chronischer Rhinosinusitis in Europa ist, desto mechanistisch wahrscheinlicher ist eine eosinophile Entzündung, die je nach Schwere mit einer quantitativen Involvierung von IL-5, IgE und IgE gegen S. aureus Enterotoxin einhergeht.

2. Es existiert ein Nebeneinander unterschiedlicher inflammatorischer Muster: zusätzlich zu Th2-Zytokinen wie IL-5 findet sich in einzelnen Clustern eine generisch-inflammatorische Aktivie- 
rung von IL-6 und IL-8, ferner IFNy und hiervon unabhängig IL-17 mit IL-22, oder IL-22 alleine.

3. Die funktionelle operative Therapie der chronischen Rhinosinusitis kann bei diesen komplexen Entzündungsmustern, welche die oberen und unteren Atemwege involvieren, nur ein Baustein unter mehreren sein und sollte idealerweise durch rationale antiinflammatorische Maßnahmen begleitet werden.

Neben diesen Th2-assoziierten Endotypen existieren wahrscheinlich neurogene inflammatorische Endotypen beim Phänotyp der nichtallergischen Entzündung, der gut auf die Therapie mit Capsaicin anspricht [141]. Die begriffliche Unschärfe wird z. B. sehr schön bei der hormonell induzierten Schwangerschaftsrhinopathie ersichtlich: es gibt einen sehr distinkten hormonellen Pathomechanismus, welcher hinreichend für eine Endotypendefinition ist, allerdings lässt sich die Erkrankung auch rein phänotypisch am Patienten definieren.

Die Ausarbeitung der Endotypen der oberen Atemwege ist im Fluss und es besteht an vielen Stellen noch kein adäquater begrifflicher Konsensus [172, 173]. Noch deutlicher ist allerdings das Defizit an Daten, welches es nun zu beheben gilt.

\subsection{Stratifizierte, nachgelagerte Prävention}

Die frühe Involvierung der Nase bei respiratorischen Erkrankungen macht die oberen Atemwege auch zu einem interessanten tertiärpräventiven Hebel.

Die allergenspezifische Immuntherapie (AIT) als klassische personalisierte Therapie ist das wichtigste Arbeitspferd in der Allergologie. Die AIT bewirkt, mutmaßlich anders als die dauerhafte Gabe therapeutischer Antikörper, einen „disease modifying effect“ und ist vor diesem Hintergrund auch als Präventionsinstrument zu betrachten.

Für die allergische Rhinitis konnte mit der randomisierten, kontrollierten und offenen Preventive Allergy Treatment Study (PAT-Studie) an 183 Kindern gezeigt werden, dass zum Zeitpunkt 5 Jahre nach Therapiebeginn die Kinder, die eine 3 jährige spezifische Immuntherapie (SIT) gegen Birken- und/oder Gräser erhalten hatten, signifikant weniger an allergischem Asthma erkrankten [odds ratio 2,68 (1,3-5,7)] [135]. Zum Zeitpunkt 10 Jahre nach Therapiebeginn zeigten sich noch günstigere Resultate mit einer odds-ratio von 4,6 95\% Cl (1,5-13,7) kein Asthma in der Immuntherapiegruppe zu entwickeln [134].

Diese Daten konnten durch Analysen von retrospektiv analysierten Versorgungsdaten aus Ostdeutschland mit einem Pool von insgesamt 118754 Patienten im Zeitraum 2006-2012 im Grunde bestätigt werden: es zeigte sich bei allergischen Patienten, die eine AIT erhielten, eine geringere Anzahl an Asthmaneuerkrankungen im Vergleich zu Allergikern, die keine AIT erhielten, das relative Risiko betrug nach Regressionsanalyse $60 \%$ (RR, 0,60; $95 \% \mathrm{Cl}, 0,42-0,84$ ), jedoch differierte das nicht-adjustierte Risiko nicht [174].

Mit der Publikation der Grass-Asthma-Prevention (GAP)-Studie konnte erstmalig in einer doppelblind-placebokontrollierten Studie ein nachgelagerter präventiver Effekt in Bezug auf Asthmasymptome für die spezifische Allergenimmuntherapie gezeigt werden. In dieser europäischen Studie wurden 812 Kinder mit einer hochdosierten Gräsertablette bzw. Placebo randomisiert und 3 Jahre immuntherapiert. Die Studie erreichte ihren primären Endpunkt, Zeitpunkt des Auftretens von Asthma durch prädefinierte reversible Verschlechterung der Lungenfunktion, nicht. Allerdings konnten konsistent und signifikant weniger Asthmasymptome und weniger
Verbrauch von Asthmamedikation (odds ratio $=0,66, p<0,036$ ) in der Verumgruppe gezeigt werden [136].

Anders als bei der spezifischen Immuntherapie der allergischen Rhinitis sind die Daten zur chronischen Rhinosinusitis sehr viel heterogener zu bewerten und die Kohorten bei Interventionen in der Regel auch deutlich kleiner. Interessant sind in diesem Zusammenhang v. a. Versorgungsstudien. So zeigen retrospektive Daten des National Health Service (NHS) im Vereinigten Königreich, dass die späte Operation von Patienten mit chronischer Rhinosinusitis häufiger zu schweren und rekurrenten Fällen sowie zu Asthma bronchiale führen kann, Marktforschungsdaten scheinen diese Daten zu stützen $[175,176]$. Eine Studie mit prospektiven Daten eines nationalen britischen Audits berichtet, dass v. a. die Patienten, die an Allergien und Asthma litten, besonders spät operiert wurden. Dieses kann sowohl an einer schleichenden Symptomadaptation und als auch möglicherweise konservativen Therapieattitüde liegen, wobei aus den Daten ersichtlich wird, dass die früh operierten Patienten bei Nachbeobachtungsvisiten nach 12 und 60 Monaten eine bessere Symptomkontrolle und krankheitsbezogene Lebensqualität aufwiesen [177]. Auch scheinen bei Patienten, die zu einem früheren Zeitpunkt operiert wurden, weniger nachgelagerte Gesundheitskosten zu entstehen [178].

Ob die Schlussfolgerung richtig ist, und eine frühe Operation von Patienten mit chronischer Rhinosinusitis vor rekurrenten Krankheitsverläufen und vor komorbidem Asthma wirklich schützt, wird sich nur durch konsistente Daten aus randomisierten Interventionsstudien, Kohorten und Versorgungsdaten demonstrieren lassen. Nur aus solchen Daten lassen sich Handlungsempfehlungen für stratifizierte Präventionsansätze im Sinne einer personalisierten Medizin gewinnen.

\section{State of the art}

Für die Therapie der Rhinosinusitis existiert im deutschen Sprachraum eine im Jahr 2017 aktualisierte S2k-Leitlinie [179] auf die an dieser Stelle verwiesen wird. Das in dritter Auflage zuletzt 2012 revidierte europäische Positionspapier EPOS entspricht dem Grunde nach in Umfang und wissenschaftlichem Anspruch einer europäischen Leitlinie und umfasst sowohl die akute als auch chronische Rhinosinusitis. Zur Therapie der allergischen Rhinitis wird das umfangreiche Dokument „Allergic Rhinitis and its Impact on Asthma“ als Standardwerk im Bereich der europäischen Allergiegesellschaft, der European Academy of Allergy and Clinical Immunology (EAACI) referenziert. Wegweisend zur kausalen Therapie der allergischen Rhinitis ist die deutsche Leitlinie zur Spezifischen Immuntherapie aus dem Jahr 2014 [129].

Der Stellenwert der funktionellen endoskopischen Nasennebenhöhlenchirurgie zur Therapie der CRS ist als hoch zu bewerten. Hierfür sprechen zum einen Versorgungsdaten aus Gesundheitssystemen mit eingeschränktem Zugang zu einer hochwertigen operativen Versorgung, zum anderen schlichtweg rationale mechanistische Überlegungen der pathologischen Anatomie der ostiomeatalen Einheit $[180,181]$. Hierbei sollte die operative Therapie in all den Fällen erfolgen, in denen mittels konservativer Therapie eine nur unzureichende Kontrolle der Symptome der CRS möglich ist und wenn ein durch Endoskopie und/oder Bildgebung gesichertes pathologisches Korrelat als zu behebendes Operationsziel definiert werden kann. Die derzeit vorliegende Evidenz ist trotz 2 rezenter Metaanalysen 
unbefriedigend $[182,183]$, da die Metaanalysen nur qualitativ hochwertige und standardisierte Studien bewerten können. Solche Studien fehlen derzeit.

Die europäische Leitlinie EPOS3 spricht auf Basis der vorliegenden Evidenzen (Level 1a) für 2 Grundpfeiler der konservativen Therapie in der chronischen Rhinosinusitis ohne Nasenpolypen eine quasi uneingeschränkte Empfehlung (Grad A Empfehlung) aus: die Therapie mit topisch-nasalen Steroiden und Nasenspülungen mit $\mathrm{NaCl}$. Bei Patienten mit chronischer Rhinosinusitis mit Nasenpolypen werden als konservative Handlungsoption topisch-nasale und orale Steroide uneingeschränkt empfohlen, in EPOS3 sind eigene Metaanalysen zur Unterstützung dieser Empfehlung hinterlegt [107].

Eine eindeutige Empfehlung zu Gunsten topischer Therapie findet sich in einer evidenzbasierten Review von Rudmik [184]. Für topische Steroide liegen zudem 2 neue Metaanalysen der Cochrane Gesellschaft vor, nachdem eine Metaanalyse wg. Vorliegen neuer Daten von Kalish [185] zurückgezogen wurde. Chong legte 2016 eine Metaanalyse vor, welche 18 randomisierte, kontrollierte Studien mit einem Pool an 2738 Patienten inkludieren konnte. Die Autoren der Metaanalyse kritisieren, dass bei den Studien für topisch nasale Steroide zwar ein moderater Effekt auf Symptome wie nasale Obstruktion und gesamte Krankheitsschwere gepoolt messbar ist, die Qualität der Evidenz, gemessen an der Anzahl der Studien und Patienten, nur moderat oder schlecht ist und die Nachbeobachtungszeiträume zu kurz sind. Ferner sei die krankheitsassoziierte Lebensqualität nicht ausreichend berücksichtigt worden [186]. Die praktisch gleiche Autorengruppe verglich zudem in einer zweiten Metaanalyse unterschiedliche intranasale topische Steroide. Auf Basis der vorliegenden Studien konnte allerdings keine Aussage zu Gunsten einzelner Substanzen oder Applikationsformen gegeben werden [187].

Eine Vielzahl von Therapien erreicht im europäischen Positionspapier eine Empfehlung der Kategorie C oder A- (nicht empfohlen). Auf Basis der neuen Metaanalysen und auch der konfirmatorischen Studien mit Biologika werden bei der nächsten Aktualisierung mit großer Wahrscheinlichkeit neue Empfehlungen implementiert werden.

Die aktuelle leitliniengerechte Therapie versorgt ohne Zweifel viele Patienten adäquat, gerade in einem sehr gut strukturierten und akzessiblen Gesundheitssystem wie in Deutschland. Allerdings zeigen uns Daten aus Phänotypisierungsstudien, dass wir zum einen sehr heterogenes Therapieansprechen sowohl bei chirurgischen als auch konservativen Therapieverfahren haben und manche Patientengruppen praktisch gar nicht profitieren [160]. Soler und Kollegen versuchten daher aufgrund eines Algorithmus mit nichtsupervidiertem maschinellen Lernen diese Gruppen prädiktiv zu identifizieren. Dieses gelang in dieser Pilotstudie partiell, führte aber zu völlig unintuitiv erfassbaren klinischen Gruppen, die zusätzlich bar eines zumindest derzeit bekannten- pathophysiologischen Korrelats sind. Dennoch müssen solche Kohorten aufgearbeitet und reproduziert werden, um eine mögliche Nutzbarkeit, auch in Algorithmen prospektiv zu überprüfen. Ein Scoring-System namens JESREC (Japanese Epidemiological Survey of Refractory Eosinophilic Chronic Rhinosinusitis) lieferte in der Zusammenschau von endoskopischen und radiologischen Befunden mit systemischer Eosinophilie in einer Kohorte mit über 1700 Patienten in Japan einen cut-off Wert, mit welchem ein diagnostisches Kriterium für eine eosinophile CRS wNP und ein erhöhtes Risiko von Rezidiven beschrieben werden kann [188]. Diese Ergebnisse sollten mit einem ggf. modifizierten Score international reproduziert werden. Ein Schwachpunkt der Studie ist, dass nicht überprüft werden konnte, wie sich Vorbehandlung mit Steroiden auf die Nutzbarkeit dieses Tests auswirkt, da mit Steroiden vorbehandelte Patienten von der Studie ausgeschlossen wurden.

Ein sog. "unmet clinical need" der aktuellen leitliniengerechten Therapie ergibt sich aus verschiedenen Gründen. Zum einen wird zunehmend deutlich, dass vermutlich über $20 \%$ der Patienten trotz leitliniengerechter, adäquater, effektiver und sicherer Therapie ihre Symptome nur partiell oder gar nicht kontrollieren können [189]. Zudem scheint der Anteil an Rezidiven jahrelang unterschätzt worden zu sein. Die Rate an Revisionsoperationen liegt im Vereinigten Königreich bei 19,1 \% für CRS und 20,6\% für CRSwNP in einem 5-Jahreszeitraum und hat sich trotz verbesserter chirurgischer Techniken und der Verfügbarkeit optimierter topischer Steroide nicht gebessert [190]. In einzelnen Kohorten erkranken bis zu $80 \%$ der Patienten mit einer CRSwNP an Rezidiven [84].

Mit großer Wahrscheinlichkeit müssen wir unsere Patienten zukünftig realistischer aufklären, allerdings brauchen wir auch besser charakterisierte klinische Kohorten. Zudem ist völlig unklar, welchen Anteil z. B. fehlende Kooperation und suboptimale Compliance bei der Einnahme topischer Steroide [191] an schweren Krankheitsverläufen hat. Die fehlende Krankheitskontrolle in diesem epidemiologisch und sozioökonomisch relevanten Kollektiv chronisch kranker Patienten mit schwerer und persistierender allergischer Rhinitis oder chronischer Rhinosinusitis ist ein derzeit nicht adäquat quantifizierter Faktor. Ein nicht unerheblicher Anteil dieser Patienten wird möglicherweise als SCUAD (Severe chronic upper airway disease) mit einem multifaktoriellen Geschehen zu bewerten sein [192].

Stratifizierte Medizin kann an dieser Stelle eine individuelle Therapie und nachgelagerte Prävention ermöglichen. Ein Mittel hierfür sind pathophysiologisch rationale und gezielte Interventionen mit Biologika.

\section{Biologika in Studien mit rhinologischen Erkrankungen}

\subsection{Allergische Rhinitis}

\subsubsection{Studien mit Omalizumab}

Die bis jetzt letzte und fünfte humane Immunglobulinklasse lgE wurde nach einem wissenschaftlichen Wettlauf zwischen Johansson und Bennich mit Kimishige und Teruko Ishizaka 1967 entdeckt. Ishizaka benannten es Immunglobilin E [193], konnten es aber nicht isolieren und charakterisieren. Das bis dahin nicht identifizierte „Reagin“ der Prausnitz-Küster Reaktion wurde durch Bennich und Johansson charakterisiert [194] und die Assoziation zu Asthma noch im gleichen Jahr gezeigt [195]. Die IgE-vermittelte Sensibilisierung gegen ein Allergen ist die pathomechanistische Grundlage der modernen Allergologie und komplettierte das durch von Pirquet gefasste Konzept der Allergie als spezifische Hypersensitivitätsreaktion [196].

Omalizumab ist ein humanisierter monoklonaler Antikörper gegen IgE und wurde 2003 von der FDA und 2005 von der Europäischen Regulierungsbehörde (damals EMEA) zur Therapie des schweren allergischen Asthma zugelassen. Mechanistische Studien zur kausalen Behandlung allergischer Erkrankungen erfüllten die Erwartungen zunächst nicht, da trotz der effektiven pharmakologischen Antagonisierung und Elimination von lgE aus dem Serum weiterhin allergische Reaktionen auftreten. 
Casale konnte in einer doppelblind und placebokontrollierten Studie bei einer Kohorte mit 536 Patienten den dosisabhängigen Effekt von Omalizumab zur Monotherapie bei Patienten mit allergischer Rhinitis gegen Ragweed zeigen [197]. Dieser Effekt konnte 2003 auch für ganzjährige Allergene bestätigt werden [198].

Mechanistisch interessant war die Kombination von Omalizumab mit allergenspezifischer Immuntherapie. Hierbei konnte Omalizumab v. a. bei der beschleunigten Aufdosierung des Allergens zur effektiven und tolerogenen Erhaltungsdosierung, der sog. Rush-Immuntherapie, die Häufigkeit und Schwere der Nebenwirkungen in der Phase der Aufdosierung deutlich reduzieren. Kopp setzte Omalizumab in einer pädiatrischen Kohorte ein und konnte in vitro eine reduzierte Freisetzung von Leukotrienen bei Kindern beobachten, die unter dem Schutz von Omalizumab gegen Pollen immuntherapiert wurden [199].

Im Rahmen einer Studie des Immune Tolerance Networks des National Institutes of Health (USA) wurde von Casale eine doppelblindplacebokontrollierte 4-Arm Studie mit einer Rush-Immuntherapie gegen Ragweedpollen in der Kombination mit und ohne Omalizumab sowie einer zweifachen Placebogruppe durchgeführt. Es wurden je Arm 39-40 Patienten randomisiert. Von insgesamt 159 Patienten beendeten 123 Patienten die Studie, die präsaisonal begann, die Pollensaison inkludierte und insgesamt 21 Wochen andauerte. Der primäre Endpunkt der Studie war der Vergleich der saisonalen Symptomscores zwischen der Gruppe mit kombinierter Gabe von Omalizumab und Allergenimmuntherapie gegen die Gruppe mit Immuntherapie alleine. Der primäre Endpunkt konnte erreicht werden, auch wenn die Effektstärke verhältnismäßig gering war $(0,61$ vs. $0,85, p=0,12)$. Zudem konnte in einer post-hoc Analyse gezeigt werden, dass die Gabe von Omalizumab die Häufigkeit von systemischen allergischen Reaktionen während der Rush-Immuntherapie um $80 \%$ und signifikant reduzierte, die Rate lag allerdings mit $25,6 \%$ in der Gruppe mit Immuntherapie ohne Omalizumab sehr hoch und basierte auf einer verblindeten Selbsteinschätzung der Patienten. Die erhöhte Wirksamkeit der kombinierten Gabe von Omalizumab mit Immuntherapie war darauf zurückzuführen, dass zum Zeitpunkt der Pollensaison Omalizumab noch weiter therapeutisch administriert wurde. Ob die Wirkung der Immuntherapie über den Zeitpunkt der systemischen Elimination von Omalizumab hinaus in der kombiniert behandelten Gruppe besser war, lässt sich anhand der publizierten Daten nicht feststellen.

In-vitro Proben von insgesamt $n=36$ Individuen aus dem selben Patientenkollektiv wurden in einer weiteren mechanistischen Studie durch Klunker et al. untersucht. Hierbei wurde ein validierter facilitated antigen binding (FAB)-Assay zur Erfassung der inhibitorischen Aktivität gegen an B-Zellen bindendes I gE gemessen. Die Bindung von IgE wurde in der Gruppe der kombiniert behandelten Patienten und in der Gruppe mit Omalizumab um nahezu $100 \%$, auch über die Pollensaison hinaus inhibiert, die Gruppe mit Immuntherapie allein erreichte eine Inhibition von $50 \%$. Mechanistisch konnte hiermit gezeigt werden, dass allergenspezifisches IgE in beiden Therapiearmen mit Omalizumab nicht mehr verfügbar war. Interessanterweise konnte der seruminhibitorische Effekt bis zum Zeitpunkt 42 Wochen nach Behandlung den Effekt aufrechterhalten und war in der kombinierten Behandlungsgruppe auch deutlich ausgeprägter [200].
Kopp publizierte 2009 eine weitere pädiatrische Studie [201], welche die klinische Effektivität der kombinierten spezifischen Immuntherapie gegen Gräserpollen mit Omalizumab demonstrieren konnte.

In der klinischen Routine hat sich die kombinierte Gabe von Omalizumab plus Allergen in Europa v. a. bei Patienten etabliert, die ein erhöhtes Sicherheitsprofil bei der spezifischen Immuntherapie benötigen. Dieses betrifft z. B. das Vorliegen eines schweren Asthma bronchiale, Urtikaria, schwere Nahrungsmittelallergien [202] oder vorbekannter Anaphylaxien. Hierbei ist zu berücksichtigen, dass nicht alle diese Anwendungen in label sind. Eine gute Übersichtsarbeit findet sich unter [203].

\subsubsection{Studien mit VAK694}

Die Induktion von regulatorischen T-Zellen, die den Transkriptionsfaktor Foxp3 exprimieren und anderen Subtypen, z. B. Tr1-Zellen, gilt als ein entscheidender Faktor im Wirkungsmechanismus der spezifischen Immuntherapie [204]. Tatsächlich ist ein Monitoring dieser T-Zellkonversion zu regulatorischen Populationen extrem schwierig und human bisher nur durch aufwändige ex-vivo Untersuchungen möglich [205, 206], ein antigenspezifisches Monitoring erfolgt nur über durchflusszytometrische Analysen mit Tetrameren oder Elispots [207, 208]. Mechanistische Studien zur spezifischen Immuntherapie konnten zeigen, dass die Induktion von regulatorischen T-Zellen mit der Sekretion inhibitorischer Zytokine wie TGF- $\beta_{1}$ und IL-10 einhergeht, IL-4, IL-5 und IL-13 sezernierende T-Zellen werden reduziert [209-212]. Während IL-5 als pro-eosinophiles Zytokin maßgeblich zur Eosinophilie allergischer Entzündungen beiträgt, induzieren IL-4 und IL-13 zum einen die Produktion von IgE in B-Zellen und haben direkte proinflammatorische Effekte auf das respiratorische Epithel [74], die Schleimsekretion sowie die Becherzellhyperplasie allergischer Entzündungen der Atemwege [213]. Mantel konnte 2007 zeigen, dass IL-4 die Induktion des Transkriptionsfaktors FoxP3 in T-Zellen und damit die Bildung von regulatorischen T-Zellen dosisabhängig in-vitro inhibiert [214]. Auf dieser Basis entstand das Konzept einer kombinierten spezifischen Immuntherapie mit einem humanen anti IL-4 Antikörper. Ziel war die Elimination des IL-4 Signals in vivo, um eine wirksamere und nachhaltigere Induktion regulatorischer T-Zellen zu erreichen. Der Antikörper VAK694 ist ein vollhumaner Antikörper gegen das Zytokin IL-4 und wurde in einer experimentellen, doppelblind-placebokontrollierten, 3 armigen Studie in Kombination mit spezifischer Immuntherapie gegen Gräser bei $n=37$ Patienten eingesetzt. Primärer Endpunkt der Studie war die kutane allergenspezifische Spätphasereaktion als antigenspezifisches Surrogat für T-Zellsuppression 12 Monate nach Therapie in vivo. Explorativer Surrogatendpunkt war die antigenspezifische Produktion von IL-4 in Elispots in vitro. Zudem wurden die T-Zellpopulationen durchflusszytometrisch charakterisiert. Die Studie war als proof-of-concept Studie angelegt und nicht zur Detektion von Symptomunterschieden zwischen den Therapiegruppen in der Pollensaison gepowert. Der primäre Endpunkt, Toleranz in der kutanen Spätphase im Vergleich zu Standardtherapie, also spezifische Immuntherapie alleine, wurde nicht erreicht, da Standardtherapie alleine eine Suppression der allergeninduzierten kutanen Spätphase von über $90 \%$ erzielte, obwohl eine subeffektive Dosierung des Allergens gewählt worden war. Das proof of concept wurde in vitro erreicht: es zeigte sich eine nachhaltige Suppression allergenspezifischer IL-4 produ- 
zierender Zellen, 12 Monate nach Ende der kombinierten Therapie und im Vergleich zu Immuntherapie alleine sowie gegen Placebo. Dieser Effekt konnte allerdings nicht im klinischen Endpunkt, der kutanen Spätphasereaktion gezeigt werden [215]. Ob die Kombination von anti-IL-4 mit spezifischer Immuntherapie weiterverfolgt wird ist ungewiss, da die Entwicklung von VAK694 angehalten wurde.

\subsection{Chronische Rhinosinusitis}

\subsubsection{Omalizumab}

Die Rolle von IgE bei Asthma, allergischer Rhinitis und atopischer Dermatitis sowie zur Parasitenabwehr wurde sehr früh beschrieben [216]. 1970 wurde erstmalig im Gewebehomogenisat IgE bei Nasenpolypen nachgewiesen [217] und von Whiteside 1975 [218] auf lokalen lymphozytären Zellen und in Korrelation zu systemischen IgE-Leveln und Atopie untersucht. Eine bereits damals adressierte Frage der lokalen IgE-Produktion in Nasenpolypen wurde ein relevanter Forschungsgegenstand in der Pathophysiologie der CRS. 2001 konnte Bachert zeigen, dass der Anteil an IgE im Gewebe mit den lokalen eosinophilen Infiltraten korrelierte [78]. Die in den frühen 2000er Jahren entdeckte Assoziation zu spezifischem IgE gegen S. aureus Enterotoxin [146, 219] bei v. a. schweren Fällen war ein weiteres Indiz für die pathophysiologische Involvierung von IgE. 2005 konnte Gevaert die lokale lgE Synthese im Gewebe dokumentieren [66]. Von hieraus war es eine logische Konsequenz, einen therapeutischen Einsatz von Omalizumab bei Patienten CRS mit Nasenpolypen in klinischen Studien zu untersuchen. Erste Fallberichte und retrospektive Fallserien finden sich bei Penn [220], Guglielmo [221] und Vennera [222], überwiegend an Patienten, die wegen ihres schweren Asthma in label mit Omalizumab behandelt wurden. Pinto und Kollegen publizierten als erste Arbeitsgruppe eine doppelblind-placebokontrollierten Studie. Die Studie konnte keine Überlegenheit des Verumarmes im Vergleich zu Placebo zeigen. Dieses lag an den Einschlusskriterien, da in diese Studie sowohl Patienten mit als auch ohne Nasenpolypen eingeschlossen wurden [223]. Eine placebokontrollierte Folgestudie mit Omalizumab bei Patienten mit CRSwNP und comorbidem Asthma über einen Therapiezeitraum von 16 Wochen von Gevaert 2013 publiziert konnte konsistent eine Reduktion des nasalen Polypenscores $(-2,67, P=0,001)$ sowie in den nasalen

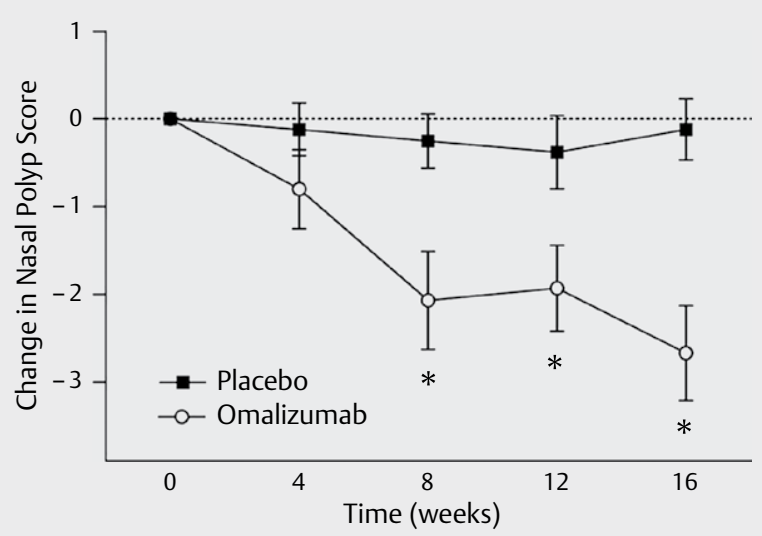

Abb. 3 Änderung des nasalen Polypenscores unter Therapie mit Omalizumab vs. Placebo (nach [224], Gevaert P., JACI 2013, Lizenz durch RightsLink/Elsevier).
Symptomscores und der krankheitsbezogenen Lebensqualität im Vergleich zu Placebo beobachten [224] ( $\mathbf{A}$ Abb. 3). Weitere Studien in dieser Indikation wurden nach Recherchen der Studienregister bereits beendet (NCT01066104), die Ergebnisse waren zum Zeitpunkt der Manuskripteinreichung nicht publiziert. Folgestudien zur CRS waren als aktiv rekrutierend zu diesem Zeitpunkt u.a. in Clinicaltrials.gov registriert.

Paradoxerweise kommt es in der Initialphase der Behandlung mit Omalizumab zu einem passageren Anstieg des Gesamt-IgE durch Bildung biologisch inaktiver aber messbarer lgE-Antikörperkomplexe. Erst nach einem Zeitraum von ca. 16 Wochen kann der pharmakodynamisch Response im Serum adäquat gemessen werden. Pharmakodynamische Untersuchungen unter Therapie Omalizumab zeigen ferner, dass die de novo IgE-Synthese unter Therapie mit Omalizumab pro Jahr um ca. 50\% fällt [225]. Zurückzuführen ist dieses über eine mögliche Änderung der IgE Homöostase aufgrund negativer feedback Mechanismen, die den niedrig-affinen IgE-Rezeptor involvieren. Aus diesem Grund ist es berechtigt, von einer möglichen zeitlichen Limitierung der Therapie und Auslassversuchen auszugehen. Hierfür müssen allerdings Langzeitdaten bewertet werden, um rationale Therapiekorridore definieren zu können.

\subsubsection{Reslizumab}

Die pathophysiologische Rolle von IL-5 bei CRSwNP westlicher Prägung wurde früh beschrieben $[76,77]$. Eine therapeutische Antagonisierung lag daher nah. Die erste Studie im Menschen und eigentliche Meilensteinstudie bei CRSwNP wurde von Gevaert 2006 publiziert. In dieser ersten doppelblind-placebokontrollierten Studie erhielten insgesamt 24 Patienten mit bilateraler CRSwNP eine medikamentöse Einmalgabe des humanisierten anti-IL-5 Antikörpers Reslizumab oder Placebo. Der Effekt auf systemische Eosinophile im Blut und ECP-Konzentrationen im Serum war bis zu 8 Wochen pharmakodynamisch nachweisbar. Lediglich die Hälfte der mit Verum behandelten Patienten zeigte einen therapeutischen Effekt auf die endoskopisch erhobenen Polypenscores. In einer post-hoc Analyse konnten Gevaert und Kollegen jedoch darlegen, dass es sich bei den Respondern um diejenigen Patienten handelte, welche zum Ausgangspunkt hohe IL-5 Konzentrationen im Nasensekret hatten. Mittels einer Regressionsanalyse konnte ein cut-off Wert für IL-5> 40 pg/ml im Nasensekret definiert werden, der einen positiven Therapieeffekt auf die Behandlung mit Reslizumab vorhersagen konnte (odds ratio, 21,0; 95\% Cl, 1,5-293,3; $P=0,009$ ). Eine multizentrische Studie mit Reslizumab in den USA untersuchte die Wirksamkeit bei schlecht kontrolliertem, eosinophilen Asthma bronchiale. Interessanterweise war Reslizumab in der Subgruppe der Asthmatiker mit vorbekannter CRSwNP wirksamer als bei Asthmatikern ohne Polypen [226]. Diese Subtypisierung entsprach quasi einer indirekten Endotypisierung. Eine weitere Studie zur CRS mit Reslizumab ist zum Zeitpunkt der Manuskripterstellung in Clinicaltrials.gov als rekrutierend registriert.

\subsubsection{Mepolizumab}

Nach ersten erfolgreichen Studien zur Behandlung des eosinophilen Asthma $[227,228]$ wurde durch Gevaert eine 2:1 randomisierte Pilotstudie von 8 Wochen Dauer mit 2 therapeutischen Gaben (je 750 mg intravenös) des humanisierten anti-IL-5 Antikörpers Mepolizumab durchgeführt. Die, gemessen an der in der EU aktuell für eosinophiles Asthma zugelassenen Dosierung (100 mg s.c.), vergleichs- 
weise hohe Dosis, wurde allerdings gut toleriert und zeigte bei einem Großteil der behandelten Patienten eine Reduktion der Polypengröße, welche konsistent auch radiologisch dokumentiert werden konnte. Von Interesse war, dass bei dieser Studie, anders als bei der Untersuchung von Reslizumab, die lokale IL-5 Konzentration im Nasensekret den Therapieerfolg nicht vorhersagen konnte [229].

2017 wurde eine europäisch-multizentrische, konfirmatorische Phase II/III Studie für Mepolizumab zur Therapie der CRSwNP von Bachert und Kollegen publiziert. Bei dieser 2009 initiierten Studie wurden europaweit 105 Patienten mit schwerer therapierefraktärer CRSwNP mit Indikationsstellung zur operativen Therapie 1:1 entweder zu 750 mg Mepolizumab oder Placebo randomisiert und erhielten 6 malig alle 4 Wochen ihre Therapie unter Fortführung der Therapie mit topisch nasalen Steroiden. Der primäre Endpunkt wurde definiert als Indikation bzw. Erfordernis zur operativen Therapie der CRSwNP zum Zeitpunkt 25 Wochen nach Beginn der Therapie. Zum Zeitpunkt 25 Wochen nach Randomisierung benötigten 30\% der Patienten unter Mepolizumab keine chirurgische Therapie mehr (ITT, 16 [30\%] vs. 5 [10\%]; P=0,006). Konsistent hiermit reduzierten sich in der verumbehandelten Gruppe auch die VAS-Scores ( -1.8 in Woche 25 (ITT 95\% Cl, 22,9 zu 20,8; P= 0,001), der SNOT-22 Test und in der post-hoc Analyse auch die endoskopischen Polypenscores (siehe auch \ Abb. 4). Auch in dieser Studie wurde Mepolizumab trotz der vergleichsweise hohen Dosierung gut toleriert. Riechen wurde auf Basis der VAS in der Verumgruppe besser, leider wurden in der Studie unterschiedliche Riechtests verwendet, weshalb dieser wichtige Zielparameter nicht systematisch verwertbar ist [230].

\subsubsection{Benralizumab}

Ähnlich wie Mepolizumab und Reslizumab inaktiviert Benralizumab funktionell die Vermittlung biologischer, überwiegend pro-eosinophiler, Effekte von IL-5 durch Bindung des therapeutischen humanisierten Antikörpers an die IL-5-alpha Untereinheit des IL-5 Rezeptors (Übersicht bei [231]). Für CRS sind derzeit keine Studien publiziert. Zum Zeitpunkt der Manuskripterstellung war eine Studie zur CRS im Studienportal Clinicaltrials.gov als aktiv und nicht rekrutierend registriert.

\subsubsection{Dupilumab}

Der vollständig humane Antikörper bindet die gemeinsame alphaUntereinheit des IL-4 und IL-13 Rezeptors und unterbricht hiermit pleiotrope Th2-Signale in multiplen immunologischen Kompartimenten. Die gute Wirksamkeit bei eosinophilem Asthma [232] und insbesondere in der Therapie des atopischen Ekzems mit auch pivotalen Studien wurde überzeugend dargelegt [233, 234]. In der Indikation CRS untersuchte ein internationales Konsortium um Bachert und Kollegen in einer Phase II/III Studie von 16 Wochen Dauer Dupilumab vs. Placebo als add-on Therapie zu topisch-nasalen Steroiden bei 60 Patienten. Im endoskopischen Polypenscore konnte eine Differenz von $(-1,6$ [95\%Cl, - 2,4 zu - 0,7]; P<0,001) von Verum im Vergleich zu Placebo gezeigt werden. Dieser Effekt war konsistent mit einer Reduktion der CT-morphologisch bestimmten LundMacKay Scores und des SNOT-22 (siehe auch - Abb. 5).

Dupilumab wurde 2017 durch die FDA zur Behandlung des atopischen Ekzems in den USA zugelassen, die Zulassung in der EU wurde durch die EMA empfohlen.
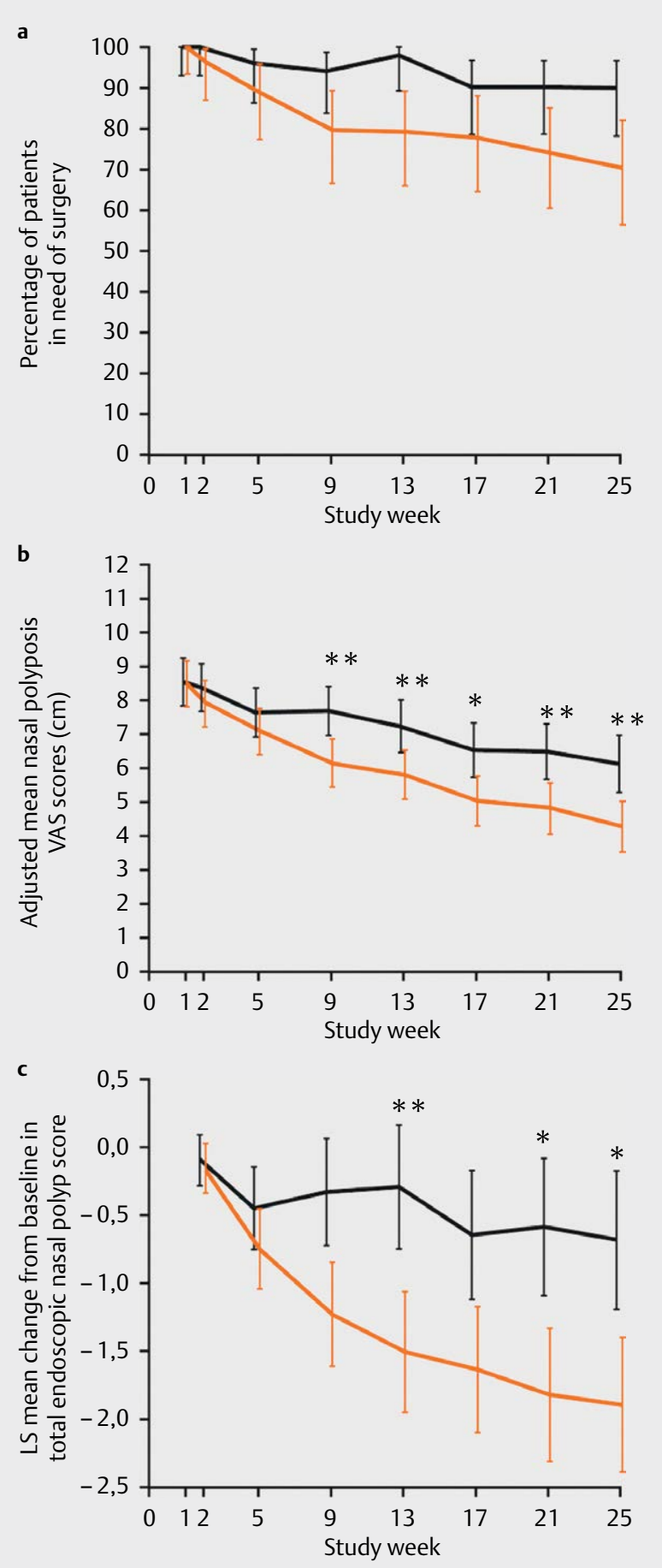

Treatment $(95 \% \mathrm{Cls}) \quad$ Placebo $\longrightarrow$ Mepolizumab -

Abb. 4 Wirksamkeit von Mepolizumab vs. Placebo bei CRSwNP: konsistente Reduktion der OP-Erfordernis, VAS-Scores und der endoskopischen Polypenscores (nach [230], Bachert C., JACI 2017, Lizenz durch RightsLink/Elsevier).

Weitere Zielstrukturen für therapeutische Antikörper werden derzeit untersucht. Hier sind z. B. anti-TSLP und anti-Siglec-8 zu nennen. Für weitere Möglichkeiten der Zytokinmodulation wird zudem eine Prüfsubstanz PF-06817024 in dieser Indikation untersucht (Quelle: Clinicaltrials.gov). 


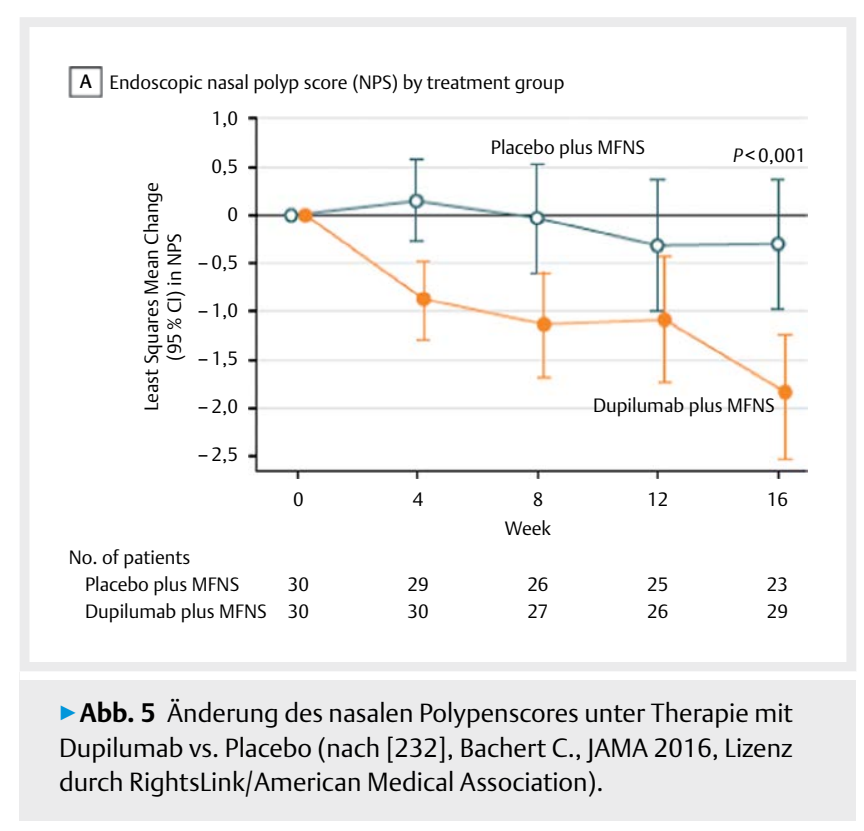

\subsection{Beispiele für seltene Indikationen}

Für Patienten mit einer eosinophilen GPA (Churg-Strauss Vaskulitis), welche häufig mit einer Beteiligung der oberen Atemwege im Sinne einer CRSwNP einhergeht, wurde in einer multizentrischen Studie von Wechsler der Einsatz von Mepolizumab evaluiert. Bei dieser Studie wurden 136 Patienten randomisiert. Der Anteil der Patienten mit Remission war in der mit Mepolizumab behandelten Gruppe deutlich höher ( $32 \%$ vs. $3 \%, 32 \%$ vs. $3 \%$; odds ratio, 16,$74 ; 95 \% \mathrm{Cl}, 3,61$ to 77,$56 ; \mathrm{P}<0,001)$, in der Verumgruppe konnte zudem die Nutzung systemischer Steroide bei über $40 \%$ der Patienten deutlich gesenkt werden. 35\% der mit Mepolizumab vs. 51 \% der mit Placebo behandelten Patienten beklagten innerhalb eines Jahres das Wiederauftreten sinunasaler Symptome. Das Nebenwirkungsprofil und die steroideinsparenden Effekte machen Mepolizumab daher zu einer interessanten Therapiealternative [152].

Für zystische Fibrose wurden mit den Chloridkanalverstärkern neue und erfolgreich klinisch geprüfte Substanzen zugelassen (siehe small molecules, 1.8.).

\subsection{Biomarker}

Eine echte Personalisierung dieser oben beschriebenen und sehr teuren Therapie durch Biomarker würde dem Anspruch der Präzisionsmedizin eher gerecht werden können, so gut als möglich jedem Patienten die richtige Therapie zum richtigen Zeitpunkt der Erkrankung zur Verfügung zu stellen. Gerade die Etablierung dieser Marker stellt sich nun sehr viel schwieriger dar. Dieses liegt aber auch an der fehlenden patentrechtlichen Schützbarkeit und dem daraus resultierenden nur geringen kommerziellen Interesse. Abseits eines umfassenden klinischen work-up bei Patienten mit CRS (siehe hierzu die aktualisierte deutsche Leitlinie [179]) sind einfache Marker eine gute Arbeitsgrundlage.

\subsubsection{Eosinophile im Vollblut und Gesamt-IgE: einfache inflammatorische Marker}

Gerade bei „westlich“ geprägten Entzündungsprofilen der CRSwNP sind die Eosinophilen sowie das Gesamt-IgE im Serum gute globale und derivative Marker der Th2-Entzündung [235], welche ubiquitär und ohne Sonderanforderung etabliert sind und partiell auch schon prospektiv in Studien wie z. B. der JESREC Kohorte (s. o.) untersucht wurden [188]. Auch ECP ist ein vielversprechender Marker, aber nicht so einfach verfügbar [140]. Größere Untersuchungen zu Sensitivität und Spezifität wären hilfreich.

\subsubsection{Explorative Biomarker}

Dieses Feld eröffnet sehr große Möglichkeiten zur stratifizierten Therapie, allerdings korrespondiert die Anzahl der identifizierten potenziellen Marker in keiner Weise mit dem Stand der Validierung, wie zuletzt auch für die vergleichsweise gut standardisierte AIT gezeigt wurde [236], allerdings sind die neuen Marker wissenschaftlich spannend und daher zu überprüfen. Experimentell zeigen z. B. sich neue Möglichkeiten auf Basis der Expression von DPP10 (Dipeptidylpeptidase 10) als Marker für AERD [237], Transglutaminase-2(TGM2) Expression im Gewebe als möglicher Marker bei AERD-negativem Endotyp [238] und auch dem WNT-Signalling [239]. Eine gute Übersicht möglicher lokaler und systemischer Biomarker in den Atemwegen findet sich bei [240].

Ein denkwürdiges Beispiel für einen Th2-assoziierten Biomarker stellt Periostin dar. Die Expression bei Patienten mit Asthma korrelierte mit dem erfolgreichen Ansprechen auf die Therapie mit dem anti-IL-13 Antikörper Lebrikizumab [241]. Leider konnten diese sehr vielversprechenden Daten in den pivotalen LAVOLTA Studien so nicht bestätigt werden [242, 243]. Ob dieses an einer Selektionsbias der Stichprobe liegt oder am Biomarker selbst, ist zu diskutieren. In einer post-hoc Biomarkerstudie wurden lokal und systemische Expression von Periostin durch die Arbeitsgruppe um Bachert in verschiedenen Therapiemodalitäten untersucht. Hierbei konnte gezeigt werden, dass die Periostinexpression die lokale und systemische Eosinophilenlast reflektiert und sowohl nach Gabe von systemischen Steroiden, als auch nach Gabe von Mepolizumab und Omalizumab bei CRSwNP im Serum und im Nasensekret reduziert war [244]. Allerdings sind nun prospektive Erhebungen gefordert.

Selbst dort, wo die Expression des lokalen pathophysiologischen Faktors naheliegend wäre, sind die Ergebnisse heterogen. So konnte in der Studie zur Behandlung der CRSwNP mit Reslizumab die lokale Expression von IL-5 den Therapieerfolg vorhersagen, bei der Therapie mit Mepolizumab ist dieser Zusammenhang bisher nicht nachgewiesen worden (s. o. 4.1) [229, 245].

Aus Sicht des Autors ist nicht davon auszugehen, dass einzelne Marker das Bild bestimmen werden. Es ist durchaus darüber zu spekulieren, dass wir HNO-Ärzte die komplexen Daten der durch hypothesenfreie Analysen gewonnenen Erkenntnisse werden verinnerlichen müssen und z. B. mit Unterstützung von Algorithmen unsere therapeutischen, auch chirurgischen Entscheidungen treffen werden.

\subsubsection{Molekulare Allergologie}

Durch die Entdeckung und Charakterisierung molekularer Allergene hat sich mit der komponentenbasierten Diagnostik auch die Präzision der Diagnosestellung deutlich verbessert. So lassen sich allergische Sensibilisierungen sehr viel akkurater diagnostizieren und er- 
lauben auch eine gewisse Aussagefähigkeit in Bezug auf das therapeutische Outcome einer AIT. Auch in der Diagnostik der Anaphylaxie oder zum Ausschluss einer Sensibilisierung gegen alphaGAL vor Gabe humanisierter Antikörper wie z. B. Cetuximab ist die komponentenbasierte Diagnostik essentiell. Die EAACI hat einen Anwendungsleitfaden erstellt [246], eine kompaktere auf die HNO fokussierte Version ist auch für Aeroallergene kürzlich publiziert worden [247].

\section{Fazit und grundsätzliche Überlegungen zur personalisierten Medizin}

„Personalized medicine“ ist, obwohl durch die WHO klar definiert, scheinbar ein Modewort geworden. Es beschreibt allerdings ein „medizinisches Modell, welches molekulare Technologien einsetzt, um die richtige therapeutische Strategie für die richtige Person zum richtigen Zeitpunkt maßzuschneidern und das zugleich die Krankheitsdisposition in der Population determiniert und zeitgemäße, stratifizierte Präventionsansätze liefert". Sowohl die individualisierte Therapie als auch die populationsbasierte Stratifizierung und Prävention spielen bei der Personalisierung eine Rolle [248]. Das Risiko, durch molekulare Stratifizierung Patienten zu vernachlässigen, sollte ernstgenommen werden. Wir determinieren in unseren Algorithmen Endotypen, ohne das volle pathophysiologische Bild zu kennen. Nebenwirkungen zu vermeiden, und Patienten nicht zu behandeln, die einen Biomarker nicht exprimieren, oder als potenzielle „non-responder" charakterisiert werden, hat mit gefühlter Individualität und Partizipation im therapeutischen Entscheidungsprozess sehr wenig gemein und dürfte nicht die Erwartung widerspiegeln, welche unsere Patienten an eine personalisierte Medizin haben. Dabei ist dieses Vorgehen für Patienten in der Onkologie inzwischen alltäglich. Ein molekularer Determinismus gefährdet zudem möglicherweise auch ein aufgeklärtes Gesundheitsverhalten [249], dabei ist der Einsatz von Biomarkern (z. B. der Blutgruppe oder der Nachweis einer allergischen Sensibilisierung) für eine stratifizierte Therapie (z. B. blutgruppenkompatible Blutprodukte, allergenspezifische Immuntherapie) eigentlich zum Standardrepertoire der modernen Medizin zugehörig [250].

Ob sich perspektivisch die Bezeichnung Personalisierte Medizin, Präzisionsmedizin oder stratifizierte Medizin (persönlicher Favorit des Autors) etabliert, bleibt abzuwarten.

Die Schwierigkeiten der Validierung molekularer Marker verdeutlicht zudem bei der Durchführung klinischer Studien weitere Probleme: kann ich bei einer hoch-selektiven Patientenauswahl und vorhandenen mechanistischen Standards überhaupt noch ethisch vertretbar, randomisiert, doppelblind und placebokontrolliert testen [248]? Das Beispiel der LAVOLTA Studien zeigt uns, dass wir zwingend konfirmatorische und pivotale Studien brauchen. Auf der anderen Seite gibt es Befürchtungen, dass Patienten nicht an Biomarkerstudien teilnehmen möchten, um nicht Opfer möglicher genetischer Diskriminierung zu werden [251].

Ein wichtiger Aspekt für uns operativ tätige HNO-Ärzte ist der Stellenwert der endoskopischen Nasennebenhöhlenchirurgie im Rahmen der personalisierten Medizin. Es ist wichtig, dass wir dieses wertvolle und sehr gut etablierte Instrument im Orchester der the- rapeutischen Möglichkeiten optimal einsetzen und zugleich hierfür die Datenbasis durch kontrollierte Studien verbessern.

Das Spannungsfeld der Begriffe zwischen personalisierter Medizin zur Präzisionsmedizin weckt Hoffnungen und impliziert eine Kontrollillusion. Medizin ist nicht nur eine Wissenschaft und kann nie völlig „präzise“ werden [252]. Konkurrierende Konnotationen, Interessen und Hoffnungen bei Patienten, Investoren und Krankenkassen erfordern einen realistischen Umgang mit den Erwartungen aber auch die aufgeklärte und proaktive Nutzung neuer therapeutischer Möglichkeiten durch eine menschliche, partizipative und rationale Medizin, auch in der Rhinologie.

Hier gibt es für uns HNO-Ärzte in der Rhinologie 2 interessante und schon jetzt umsetzbare Perspektiven: die an verhältnismäßig einfachen Biomarkern orientierte molekulare Therapie der chronischen Rhinosinusitis durch neue Biologika sowie die durch komponentenbasierte Allergiediagnostik präzisierte spezifische Immuntherapie.

\section{Interessenkonflikt}

Adam Chaker führt über die Technische Universität München Beratungsleistungen (z.B. Advisory Boards), Vorträge oder weitere Aktivitäten für Allergopharma, ALK-Abello, GSK, HAL Allergy, Mundipharma und Lofarma durch; hat klinische Studien oder Forschungsgelder über die Technische Universität München erhalten von ALK, Allergopharma, Novartis, Bencard/Allergen Therapeutics, ASIT Biotech, GSK, Roche, und Zeller AG, ferner vom Umweltbundesamt der Bundesrepublik Deutschland und DZL (BMBF). AMC hat ferner Honorare und Reisekostenerstattungen erhalten vom Bayerischen Ärzteblatt, der Deutschen Gesellschaft für Allergologie und klinische Immunologie (DGAKI) und der European Academy of Allergy and Clinical Immunology.

Literatur

[1] Boyman O et al. EAACI IG Biologicals task force paper on the use of biologic agents in allergic disorders. Allergy 2015; 70: 727-754

[2] Agency EM. EMA GUIDELINE ON SIMILAR BIOLOGICAL MEDICINAL PRODUCTS. 2005 (http://www.ema.europa.eu/docs/en_GB/ document_library/Scientific_guideline/2009/09/WC500003517.pdf (10th of October, 2017))

[3] Kohler G, Milstein C. Continuous cultures of fused cells secreting antibody of predefined specificity. Nature 1975; 256: 495-497

[4] Quianzon CC, Cheikh I. History of insulin. J Community Hosp Intern Med Perspect 2012; 2

[5] Suiter TM. First and next generation native rFVIII in the treatment of hemophilia A. What has been achieved? Can patients be switched safely? Semin Thromb Hemost 2002; 28: 277-284

[6] Beauvais P, Billette de Villemeur T. Prion diseases and blood transfusion. Transfus Clin Biol 1999; 6: 24-28

[7] Frasier SD. The not-so-good old days: working with pituitary growth hormone in North America, 1956 to 1985. J Pediatr 1997; 131: S1-S4

[8] Ayyar VS. History of growth hormone therapy. Indian J Endocrinol Metab 2011; 15: (Suppl 3): S162-S165

[9] Mosmann TR et al. Two types of murine helper T cell clone. I. Definition according to profiles of lymphokine activities and secreted proteins. J Immunol 1986; 136: 2348-2357 
[10] Mosmann TR, Coffman RL. TH1 and TH2 cells: different patterns of lymphokine secretion lead to different functional properties. Annu Rev Immunol 1989; 7: 145-173

[11] Bryan SA et al. Effects of recombinant human interleukin-12 on eosinophils, airway hyper-responsiveness, and the late asthmatic response. Lancet 2000; 356: 2149-2153

[12] Friedrich $M$ et al. Immunomodulation by interleukin-10 therapy decreases the incidence of relapse and prolongs the relapse-free interval in Psoriasis. J Invest Dermatol 2002; 118: 672-677

[13] Trepicchio WL et al. Interleukin-11 therapy selectively downregulates type I cytokine proinflammatory pathways in psoriasis lesions. J Clin Invest 1999; 104: 1527-1537

[14] Goel N, Chance K. Biosimilars in rheumatology: understanding the rigor of their development. Rheumatology (Oxford) 2017; 56: 187-197

[15] Dorvignit D et al. Expression and biological characterization of an anti-CD20 biosimilar candidate antibody: a case study. MAbs 2012; 4: 488-496

[16] Elliott M] et al. Randomised double-blind comparison of chimeric monoclonal antibody to tumour necrosis factor alpha (cA2) versus placebo in rheumatoid arthritis. Lancet 1994; 344: 1105-1110

[17] Taylor PC. Developing anti-TNF and biologic agents. Rheumatology (Oxford) 2011; 50: 1351-1353

[18] Upchurch KS, Kay J. Evolution of treatment for rheumatoid arthritis. Rheumatology (Oxford) 2012; 51: (Suppl 6): vi28-vi36

[19] Roque-Navarro L et al. Humanization of predicted T-cell epitopes reduces the immunogenicity of chimeric antibodies: new evidence supporting a simple method. Hybrid Hybridomics 2003; 22: 245-257

[20] Croft M, Benedict CA, Ware CF. Clinical targeting of the TNF and TNFR superfamilies. Nat Rev Drug Discov 2013; 12: 147-168

[21] Parren P, Carter P], Pluckthun A. Changes to International Nonproprietary Names for antibody therapeutics 2017 and beyond: of mice, men and more. MAbs 2017; 9: 898-906

[22] Vultaggio A et al. Manifestations of Antidrug Antibodies Response: Hypersensitivity and Infusion Reactions. J Interferon Cytokine Res 2014; 34: 946-952

[23] Vultaggio A et al. Circulating T cells to infliximab are detectable mainly in treated patients developing anti-drug antibodies and hypersensitivity reactions. Clin Exp Immunol 2016; 186: 364-372

[24] Robert F et al. Phase I study of anti-epidermal growth factor receptor antibody cetuximab in combination with radiation therapy in patients with advanced head and neck cancer. J Clin Oncol 2001; 19: 3234-3243

[25] Bourhis J et al. Phase I/II study of cetuximab in combination with cisplatin or carboplatin and fluorouracil in patients with recurrent or metastatic squamous cell carcinoma of the head and neck. J Clin Oncol 2006; 24: 2866-2872

[26] Bonner JA et al. Radiotherapy plus cetuximab for squamous-cell carcinoma of the head and neck. N Engl J Med 2006; 354: 567-578

[27] O'Neil BH et al. High incidence of cetuximab-related infusion reactions in Tennessee and North Carolina and the association with atopic history. J Clin Oncol 2007; 25: 3644-3648

[28] Chung $\mathrm{CH}$ et al. Cetuximab-induced anaphylaxis and IgE specific for galactose-alpha-1,3-galactose. N Engl ] Med 2008; 358: 1109-1117

[29] Budach W, Bolke E, Homey B. Severe cutaneous reaction during radiation therapy with concurrent cetuximab. N Engl J Med 2007; 357: 514-515

[30] Commins SP, Platts-Mills TA. Delayed anaphylaxis to red meat in patients with IgE specific for galactose alpha-1,3-galactose (alpha-gal). Curr Allergy Asthma Rep 2013; 13: 72-77

[31] Commins SP, Platts-Mills TA. Tick bites and red meat allergy. Curr Opin Allergy Clin Immunol 2013; 13: 354-359
[32] Galili U. The alpha-gal epitope and the anti-Gal antibody in xenotransplantation and in cancer immunotherapy. Immunol Cell Biol 2005; 83: 674-686

[33] Fischer J et al. Galactose-alpha-1,3-galactose sensitization is a prerequisite for pork-kidney allergy and cofactor-related mammalian meat anaphylaxis. J Allergy Clin Immunol 2014; 134: 755-759 e1

[34] Kleponis ], Skelton R, Zheng L. Fueling the engine and releasing the break: combinational therapy of cancer vaccines and immune checkpoint inhibitors. Cancer Biol Med 2015; 12: 201-208

[35] Perez-Alvarez R et al. Biologics-induced autoimmune diseases. Curr Opin Rheumatol 2013; 25: 56-64

[36] Weise $\mathrm{M}$ et al. Biosimilars: the science of extrapolation. Blood 2014; 124: 3191-3196

[37] Ledford H. First biosimilar drug set to enter US market. Nature 2015; 517: $253-254$

[38] Kurki P et al. Interchangeability of Biosimilars: A European Perspective. BioDrugs 2017; 31: 83-91

[39] Agency EM. Guideline on similar biological medicinal products. 2013 (http://www.ema.europa.eu/docs/en_GB/document_library/ Scientific_guideline/2014/10/WC500176768.pdf) Accessed on 10th October 2017

[40] Glue P et al. Pegylated interferon-alpha2b: pharmacokinetics, pharmacodynamics, safety, and preliminary efficacy data. Hepatitis C Intervention Therapy Group. Clin Pharmacol Ther 2000; 68: 556-567

[41] Mok TS et al. Gefitinib or carboplatin-paclitaxel in pulmonary adenocarcinoma. N Engl J Med 2009; 361: 947-957

[42] Krueger J et al. Tofacitinib attenuates pathologic immune pathways in patients with psoriasis: A randomized phase 2 study. J Allergy Clin Immunol 2016; 137: 1079-1090

[43] Aguilar-Pimentel A et al. Improved efficacy of allergen-specific immunotherapy by JAK inhibition in a murine model of allergic asthma. PLoS One 2017; 12: e0178563

[44] Boyle MP, De Boeck K. A new era in the treatment of cystic fibrosis: correction of the underlying CFTR defect. Lancet Respir Med 2013; 1 : $158-163$

[45] Quon BS, Wilcox PG. A new era of personalized medicine for cystic fibrosis - at last! Can Respir ] 2015; 22: 257-260

[46] Krug $\mathrm{N}$ et al. Allergen-induced asthmatic responses modified by a GATA3-specific DNAzyme. N Engl J Med 2015; 372: 1987-1995

[47] IMS Institute for Healthcare Informatics, Delivering on the Potentialof Biosimilar Medicines; The Role of Functioning Competitive Markets. 2016 (http://www.medicinesforeurope.com/wp-content/uploads/ 2016/03/IMS-Institute-Biosimilar-Report-March-2016-FINAL.pdf am 04.01.2018)

[48] GKV Spitzenverband Deutschland. Biosimilars aus Sicht der Kostenträger. 2016 https://www.bfarm.de/SharedDocs/Downloads/ DE/Service/Termine-und-Veranstaltungen/dialogveranstaltungen/ dialog_2016/160627/08_Folien_Haas.pdf? blob=publicationFile \&v=2 zuletzt am 04.01.2018)

[49] Health, I. Impact of Biosimilar Competion 2016. 2016 (https://www. imshealth.com/files/web/Market Insights/IMS_Health_Impact_of_Biosimilar_Competition_EU_2016.pdf online am 10.10.2017)

[50] Chaker AM, Wagenmann M. Schleimhaut der Nase. Allergo ] 2014; 23: 14

[51] Pabst R, Chaker A. Integriertes Schleimhautimmunsystem der oberen Atemwege: Intraepitheliale Lymphozyten, NALT und der Waldeyersche Rachenring. Biedermann, Heppt, Renz, Röcken: Allergologie 2016; 1: 147-155

[52] Bachert C, Holtappels G. Pathophysiology of chronic rhinosinusitis, pharmaceutical therapy options. Laryngorhinootologie 2015; 94 : (Suppl 1): S32-S63

[53] Afzelius BA. Cilia-related diseases. J Pathol 2004; 204: 470-477 
[54] Stanke F. The Contribution of the Airway Epithelial Cell to Host Defense. Mediators Inflamm 2015; 2015: 463016

[55] Sisson JH et al. Smoke and viral infection cause cilia loss detectable by bronchoalveolar lavage cytology and dynein ELISA. Am J Respir Crit Care Med 1994; 149: 205-213

[56] Ganz T, Lehrer RI. Defensins. Pharmacol Ther 1995; 66: 191-205

[57] Radicioni $G$ et al. The innate immune properties of airway mucosal surfaces are regulated by dynamic interactions between mucins and interacting proteins: the mucin interactome. Mucosal Immunol 2016; 9: $1442-1454$

[58] Cobo ER et al. Colonic MUC2 mucin regulates the expression and antimicrobial activity of beta-defensin 2. Mucosal Immunol 2015; 8: 1360-1372

[59] Delacroix DL et al. IgA subclasses in various secretions and in serum. Immunology 1982; 47: 383-385

[60] Brandtzaeg P. Pillars Article: Mucosal and Glandular Distribution of Immunoglobulin Components: Differential Localization of Free and Bound SC in Secretory Epithelial Cells. J. Immunol. 1974. 112: 1553-1559. J Immunol 2017; 198: 1768-1774

[61] Macpherson AJ et al. The immune geography of IgA induction and function. Mucosal Immunol 2008; 1: 11-22

[62] Pawankar RU et al. Phenotypic and molecular characteristics of nasal mucosal gamma delta $T$ cells in allergic and infectious rhinitis. Am J Respir Crit Care Med 1996; 153: 1655-1665

[63] Mjosberg JM et al. Human IL-25- and IL-33-responsive type 2 innate lymphoid cells are defined by expression of CRTH2 and CD161. Nat Immunol 2011; 12: 1055-1062

[64] Brandtzaeg P, Pabst R. Let's go mucosal: communication on slippery ground. Trends Immunol 2004; 25: 570-577

[65] Chaker AM. Anatomy and Microanatomy of Tonsils. Encyclopedia of Immunobiology 2016; 3: 420-426

[66] Gevaert P et al. Organization of secondary lymphoid tissue and local IgE formation to Staphylococcus aureus enterotoxins in nasal polyp tissue. Allergy 2005; 60: 71-79

[67] Fokkens W] et al. Langerhans cells in nasal mucosa of patients with grass pollen allergy. Immunobiology 1991; 182: 135-142

[68] Fokkens W] et al. Characterization and quantification of cellular infiltrates in nasal mucosa of patients with grass pollen allergy, non-allergic patients with nasal polyps and controls. Int Arch Allergy Appl Immunol 1990; 93: 66-72

[69] Jahnsen FL et al. Human nasal mucosa contains antigen-presenting cells of strikingly different functional phenotypes. Am J Respir Cell Mol Biol 2004; 30: 31-37

[70] Allam JP et al. Comparative analysis of nasal and oral mucosa dendritic cells. Allergy 2006; 61: 166-172

[71] Soyka MB et al. Defective epithelial barrier in chronic rhinosinusitis: the regulation of tight junctions by IFN-gamma and IL-4. J Allergy Clin Immunol 2012; 130: 1087-1096 e10

[72] Zhou B et al. Thymic stromal lymphopoietin as a key initiator of allergic airway inflammation in mice. Nat Immunol 2005; 6: 1047-1053

[73] Xu G et al. Opposing roles of IL-17 A and IL-25 in the regulation of TSLP production in human nasal epithelial cells. Allergy 2010; 65: 581-589

[74] Zissler UM et al. Interleukin-4 and interferon-gamma orchestrate an epithelial polarization in the airways. Mucosal Immunol 2016; 9: 917-926

[75] Soyka MB et al. The Induction of IL-33 in the Sinus Epithelium and Its Influence on T-Helper Cell Responses. PLoS One 2015; 10: e0123163

[76] Bachert C et al. IL-5 synthesis is upregulated in human nasal polyp tissue. J Allergy Clin Immunol 1997; 99: 837-842
[77] Van Zele T et al. Differentiation of chronic sinus diseases by measurement of inflammatory mediators. Allergy 2006; 61: $1280-1289$

[78] Bachert C et al. Total and specific IgE in nasal polyps is related to local eosinophilic inflammation. J Allergy Clin Immunol 2001; 107: 607-614

[79] Linneberg A et al. The link between allergic rhinitis and allergic asthma: a prospective population-based study. The Copenhagen Allergy Study. Allergy 2002; 57: 1048-1052

[80] Anderson HR, Bland JM, Peckham CS. Risk factors for asthma up to 16 years of age. Evidence from a national cohort study. Chest 1987; 91 (6 Suppl): 127S-130S

[81] Shaaban $R$ et al. Rhinitis and onset of asthma: a longitudinal population-based study. Lancet 2008; 372: 1049-1057

[82] Jarvis $\mathrm{D}$ et al. Asthma in adults and its association with chronic rhinosinusitis: the GA2LEN survey in Europe. Allergy 2012; 67: 91-98

[83] Settipane GA, Chafee FH. Nasal polyps in asthma and rhinitis. A review of 6,037 patients. J Allergy Clin Immunol 1977; 59: 17-21

[84] Bachert C, Zhang L, Gevaert P. Current and future treatment options for adult chronic rhinosinusitis: Focus on nasal polyposis. J Allergy Clin Immunol 2015; 136: 1431-1440

[85] Williamson PA et al. Airway dysfunction in nasal polyposis: a spectrum of asthmatic disease? Clin Exp Allergy 2011; 41: 1379-1385

[86] Hens $G$ et al. Sinonasal pathology in nonallergic asthma and COPD: 'united airway disease' beyond the scope of allergy. Allergy 2008; 63: 261-267

[87] Spergel JM, Paller AS. Atopic dermatitis and the atopic march. J Allergy Clin Immunol 2003; 112 (6 Suppl): S118-S127

[88] Braunstahl G] et al. Segmental bronchial provocation induces nasal inflammation in allergic rhinitis patients. Am J Respir Crit Care Med 2000; 161: 2051-2057

[89] Braunstahl G] et al. Nasal allergen provocation induces adhesion molecule expression and tissue eosinophilia in upper and lower airways. J Allergy Clin Immunol 2001; 107: 469-476

[90] Braunstahl G] et al. Segmental bronchoprovocation in allergic rhinitis patients affects mast cell and basophil numbers in nasal and bronchial mucosa. Am J Respir Crit Care Med 2001; 164: 858-865

[91] Assanasen P et al. The nasal passage of subjects with asthma has a decreased ability to warm and humidify inspired air. Am J Respir Crit Care Med 2001; 164: 1640-1646

[92] Naclerio RM et al. Observations on the ability of the nose to warm and humidify inspired air. Rhinology 2007; 45: 102-111

[93] Eccles R. Is the common cold a clinical entity or a cultural concept? Rhinology 2013; 51: 3-8

[94] Lewis-Rogers N, Bendall ML, Crandall KA. Phylogenetic relationships and molecular adaptation dynamics of human rhinoviruses. Mol Biol Evol 2009; 26: 969-981

[95] Palmenberg AC et al. Sequencing and analyses of all known human rhinovirus genomes reveal structure and evolution. Science 2009; 324: $55-59$

[96] Caliskan $M$ et al. Rhinovirus wheezing illness and genetic risk of childhood-onset asthma. N Engl J Med 2013; 368: 1398-1407

[97] Bianco $A$ et al. Th2 cytokines exert a dominant influence on epithelial cell expression of the major group human rhinovirus receptor, ICAM-1. Eur Respir J 1998; 12: 619-626

[98] Xepapadaki $P$ et al. Duration of postviral airway hyperresponsiveness in children with asthma: effect of atopy. J Allergy Clin Immunol 2005; 116: 299-304

[99] Toussaint $\mathrm{M}$ et al. Host DNA released by NETosis promotes rhinovirus-induced type-2 allergic asthma exacerbation. Nat Med 2017; 23: 681-691 
[100] Bartlett NW et al. Mouse models of rhinovirus-induced disease and exacerbation of allergic airway inflammation. Nat Med 2008; 14 : 199-204

[101] Institut, R.K. Influenza. Robert Koch Website, online am 10.10.2017: p. http://www.rki.de/DE/Content/InfAZ/I/Influenza/IPV/IPV_Node. html

[102] Zomer-Kooijker $\mathrm{K}$ et al. Increased risk of wheeze and decreased lung function after respiratory syncytial virus infection. PLoS One 2014; 9: e87162

[103] Sigurs $\mathrm{N}$ et al. Respiratory syncytial virus bronchiolitis in infancy is an important risk factor for asthma and allergy at age 7. Am J Respir Crit Care Med 2000; 161: 1501-1507

[104] American Academy of Pediatrics Committee on Infectious, D. and C. American Academy of Pediatrics Bronchiolitis Guidelines, Updated guidance for palivizumab prophylaxis among infants and young children at increased risk of hospitalization for respiratory syncytial virus infection. Pediatrics 2014; 134: e620-e638

[105] Heinecke L et al. Induction of B7-H1 and B7-DC expression on airway epithelial cells by the Toll-like receptor 3 agonist double-stranded RNA and human rhinovirus infection: In vivo and in vitro studies. J Allergy Clin Immunol 2008; 121: 1155-1160

[106] Seshadri S et al. Increased expression of the epithelial anion transporter pendrin/SLC26A4 in nasal polyps of patients with chronic rhinosinusitis. J Allergy Clin Immunol 2015; 136: 1548-1558 e7

[107] Fokkens W] et al. EPOS 2012: European position paper on rhinosinusitis and nasal polyps 2012. Rhinology 2012; 50: (Suppl 23): 1-305

[108] Wang DY et al. A survey on the management of acute rhinosinusitis among Asian physicians. Rhinology 2011; 49: 264-271

[109] Revai K et al. Incidence of acute otitis media and sinusitis complicating upper respiratory tract infection: the effect of age. Pediatrics 2007; 119: e1408-e1412

[110] Wang JH, Kwon HJ, Jang Y]. Rhinovirus enhances various bacterial adhesions to nasal epithelial cells simultaneously. Laryngoscope 2009; 119: 1406-1411

[111] Woytschak J et al. Type 2 Interleukin-4 Receptor Signaling in Neutrophils Antagonizes Their Expansion and Migration during Infection and Inflammation. Immunity 2016; 45: 172-184

[112] Cohen $\mathrm{M}$ et al. Biofilms in chronic rhinosinusitis: a review. Am J Rhinol Allergy 2009; 23: 255-260

[113] Abreu NA et al. Sinus microbiome diversity depletion and Corynebacterium tuberculostearicum enrichment mediates rhinosinusitis. Sci Transl Med 2012; 4: 151ra124

[114] Choi EB et al. Decreased diversity of nasal microbiota and their secreted extracellular vesicles in patients with chronic rhinosinusitis based on a metagenomic analysis. Allergy 2014; 69: 517-526

[115] Corriveau MN et al. Detection of Staphylococcus aureus in nasal tissue with peptide nucleic acid-fluorescence in situ hybridization. Am J Rhinol Allergy 2009; 23: 461-465

[116] Song W] et al. Staphylococcal enterotoxin sensitization in a community-based population: a potential role in adult-onset asthma. Clin Exp Allergy 2014; 44: 553-562

[117] Akdis $\mathrm{M}$ et al. Skin homing (cutaneous lymphocyte-associated antigen-positive) CD8 + T cells respond to superantigen and contribute to eosinophilia and IgE production in atopic dermatitis. J Immunol 1999; 163: 466-475

[118] Vrieze A et al. Transfer of intestinal microbiota from lean donors increases insulin sensitivity in individuals with metabolic syndrome. Gastroenterology 2012; 143: 913-916 e7

[119] Hastan D et al. Chronic rhinosinusitis in Europe--an underestimated disease. A GA(2)LEN study. Allergy 2011; 66: 1216-1223

[120] Beule AG. [Epidemiology of chronic rhinosinusitis, selected risk factors, comorbidities and economic burden]. Laryngorhinootologie 2015; 94: (Suppl 1): S1-S23
[121] Bousquet ] et al. Allergic Rhinitis and its Impact on Asthma (ARIA): achievements in 10 years and future needs. J Allergy Clin Immunol 2012; 130: 1049-1062

[122] Bousquet J et al. Allergic Rhinitis and its Impact on Asthma (ARIA) 2008 update (in collaboration with the World Health Organization, GA(2)LEN and AllerGen). Allergy 2008; 63: (Suppl 86): 8-160

[123] Pearce $N$ et al. Self-reported prevalence of asthma symptoms in children in Australia, England, Germany and New Zealand: an international comparison using the ISAAC protocol. Eur Respir J 1993; 6: $1455-1461$

[124] Langen U, Schmitz R, Steppuhn H. Prevalence of allergic diseases in Germany: results of the German Health Interview and Examination Survey for Adults (DEGS1). Bundesgesundheitsblatt Gesundheitsforschung Gesundheitsschutz 2013; 56: 698-706

[125] Haftenberger $M$ et al. Prevalence of sensitisation to aeraoallergens and food allergens: results of the German Health Interview and Examination Survey for Adults (DEGS1). Bundesgesundheitsblatt Gesundheitsforschung Gesundheitsschutz 2013; 56: 687-697

[126] Schmitz R, Kuhnert R, Thamm M. 12-Monats-Prävalenz von Allergien in Deutschland. Journal of Health Monitoring 2017; 2: 77-82

[127] Meltzer EO et al. Sleep, quality of life, and productivity impact of nasal symptoms in the United States: findings from the Burden of Rhinitis in America survey. Allergy Asthma Proc 2009; 30: 244-254

[128] Biermann J, MHF Wehrmann W, Klimek L, Wasem J. Allergische Erkrankungen der Atemwege- Ergebnisse einer umfassenden Patientenkohorte in der deutschen gesetzlichen Krankenversicherung. Allergo Journal 2013; 22: 363-373

[129] Pfaar $O$ et al. Guideline on allergen-specific immunotherapy in IgE-mediated allergic diseases: S2k Guideline of the German Society for Allergology and Clinical Immunology (DGAKI), the Society for Pediatric Allergy and Environmental Medicine (GPA), the Medical Association of German Allergologists (AeDA), the Austrian Society for Allergy and Immunology (OGAI), the Swiss Society for Allergy and Immunology (SGAI), the German Society of Dermatology (DDG), the German Society of Oto- Rhino-Laryngology, Head and Neck Surgery (DGHNO-KHC), the German Society of Pediatrics and Adolescent Medicine (DGKJ), the Society for Pediatric Pneumology (GPP), the German Respiratory Society (DGP), the German Association of ENT Surgeons (BV-HNO), the Professional Federation of Paediatricians and Youth Doctors (BVKJ), the Federal Association of Pulmonologists (BDP) and the German Dermatologists Association (BVDD). Allergo J Int 2014; 23: 282-319

[130] Calderon MA et al. Allergen injection immunotherapy for seasonal allergic rhinitis. Cochrane Database Syst Rev 2007; CD001936

[131] Radulovic $S$ et al. Sublingual immunotherapy for allergic rhinitis. Cochrane Database Syst Rev 2010; CD002893

[132] Radulovic $S$ et al. Systematic reviews of sublingual immunotherapy (SLIT). Allergy 2011; 66: 740-752

[133] Nelson $\mathrm{H}$ et al. Network meta-analysis shows commercialized subcutaneous and sublingual grass products have comparable efficacy. J Allergy Clin Immunol Pract 2015; 3: 256-266 e3

[134] Jacobsen L et al. Specific immunotherapy has long-term preventive effect of seasonal and perennial asthma: 10-year follow-up on the PAT study. Allergy 2007; 62: 943-948

[135] Niggemann B et al. Five-year follow-up on the PAT study: specific immunotherapy and long-term prevention of asthma in children. Allergy 2006; 61: 855-859

[136] Valovirta E et al. Results from the 5-year SQ grass sublingual immunotherapy tablet asthma prevention (GAP) trial in children with grass pollen allergy. J Allergy Clin Immunol 2017 Jul 6. pii: S0091-6749(17)31088-6 
[137] Kurukulaaratchy RJ et al. Identifying the heterogeneity of young adult rhinitis through cluster analysis in the Isle of Wight birth cohort. J Allergy Clin Immunol 2015; 135: 143-150

[138] Glowania A, CM Klimek L, Chaker A. Rhinitis - allergic or not? Allergo Journal 2012; 08: 486-498

[139] Hellings PW et al. Non-allergic rhinitis: Position paper of the European Academy of Allergy and Clinical Immunology. Allergy 2017 72: 1657-1665

[140] Becker $S$ et al. Non-allergic rhinitis with eosinophilia syndrome is not associated with local production of specific lgE in nasal mucosa. Eur Arch Otorhinolaryngol 2016; 273: 1469-1475

[141] Van Gerven L et al. Capsaicin treatment reduces nasal hyperreactivity and transient receptor potential cation channel subfamily $\mathrm{V}$, receptor 1 (TRPV1) overexpression in patients with idiopathic rhinitis. J Allergy Clin Immunol 2014; 133: 1332-1339 e1-e3

[142] Wagenmann M, Scheckenbach K, Chaker AM. Endotypes in Chronic Rhinosinusitis: Biomarkers Based on a Mechanistic Insight for Targeted Treatment? ORL J Otorhinolaryngol Relat Spec 2017; 79: 78-84

[143] Hirsch AG et al. Nasal and sinus symptoms and chronic rhinosinusitis in a population-based sample. Allergy 2017; 72: 274-281

[144] Rudmik L, Smith TL. Quality of life in patients with chronic rhinosinusitis. Curr Allergy Asthma Rep 2011; 11: 247-252

[145] Rajan JP et al. Prevalence of aspirin-exacerbated respiratory disease among asthmatic patients: A meta-analysis of the literature. J Allergy Clin Immunol 2015; 135 (676/81): e1

[146] Zhang $\mathrm{N}$ et al. An update on the impact of Staphylococcus aureus enterotoxins in chronic sinusitis with nasal polyposis. Rhinology 2005; 43: 162-168

[147] Knopf A et al. Rheumatic disorders affecting the head and neck: underestimated diseases. Rheumatology (Oxford) 2011; 50: 2029-2034

[148] Hofauer B et al. [Liposomal local therapy of sinunasal symptoms in ANCA associated vasculitis]. Laryngorhinootologie 2014; 93: 461-466

[149] Woywodt A, Matteson EL. Wegener's granulomatosis--probing the untold past of the man behind the eponym. Rheumatology (Oxford) 2006; 45: 1303-1306

[150] Craven A et al. ACR/EULAR-endorsed study to develop Diagnostic and Classification Criteria for Vasculitis (DCVAS). Clin Exp Nephrol 2013; 17: 619-621

[151] Yates $M$ et al. EULAR/ERA-EDTA recommendations for the management of ANCA-associated vasculitis. Ann Rheum Dis 2016; 75 : 1583-1594

[152] Wechsler ME et al. Mepolizumab or Placebo for Eosinophilic Granulomatosis with Polyangiitis. N Engl J Med 2017; 376: 19211932

[153] De Gaudemar I et al. Is nasal polyposis in cystic fibrosis a direct manifestation of genetic mutation or a complication of chronic infection? Rhinology 1996; 34: 194-197

[154] Claeys S et al. Nasal polyps in patients with and without cystic fibrosis: a differentiation by innate markers and inflammatory mediators. Clin Exp Allergy 2005; 35: 467-472

[155] Steinke JW, Borish L. Chronic rhinosinusitis phenotypes. Ann Allergy Asthma Immunol 2016; 117: 234-240

[156] Kartagener M. Zur Pathogenese der Bronchektasien bei Situs viscerum inversus. Beiträge Klin. Tuberk 1933; 83: 489-511

[157] Degano B et al. Expression of nitric oxide synthases in primary ciliary dyskinesia. Hum Pathol 2011; 42: 1855-1861

[158] Marthin JK, Nielsen KG. Choice of nasal nitric oxide technique as first-line test for primary ciliary dyskinesia. Eur Respir J 2011; 37 559-565
[159] Joensen $O$ et al. Exhaled breath analysis using electronic nose in cystic fibrosis and primary ciliary dyskinesia patients with chronic pulmonary infections. PLoS One 2014; 9: e115584

[160] Soler ZM et al. Cluster analysis and prediction of treatment outcomes for chronic rhinosinusitis. J Allergy Clin Immunol 2016; 137: 1054-1062

[161] Derycke L et al. Mixed T helper cell signatures in chronic rhinosinusitis with and without polyps. PLoS One 2014; 9: e97581

[162] Zhang $N$ et al. Different types of T-effector cells orchestrate mucosal inflammation in chronic sinus disease. J Allergy Clin Immunol 2008; 122: 961-968

[163] Katotomichelakis M et al. Inflammatory patterns in upper airway disease in the same geographical area may change over time. Am J Rhinol Allergy 2013; 27: 354-360

[164] Ba L et al. The association between bacterial colonization and inflammatory pattern in Chinese chronic rhinosinusitis patients with nasal polyps. Allergy 2011; 66: 1296-1303

[165] Derycke L et al. IL-17 A as a regulator of neutrophil survival in nasal polyp disease of patients with and without cystic fibrosis. J Cyst Fibros 2012; 11: 193-200

[166] Wen W et al. Increased neutrophilia in nasal polyps reduces the response to oral corticosteroid therapy. J Allergy Clin Immunol 2012; 129: $1522-1528$ e5

[167] Milara J et al. Mucin 1 downregulation associates with corticosteroid resistance in chronic rhinosinusitis with nasal polyps. J Allergy Clin Immunol 2015; 135: 470-476

[168] Anderson GP. Endotyping asthma: new insights into key pathogenic mechanisms in a complex, heterogeneous disease. Lancet 2008; 372: 1107-1119

[169] Lotvall J et al. Asthma endotypes: a new approach to classification of disease entities within the asthma syndrome. J Allergy Clin Immunol 2011; 127: 355-360

[170] Wenzel SE. Complex phenotypes in asthma: current definitions. Pulm Pharmacol Ther 2013; 26: 710-715

[171] Tomassen P et al. Inflammatory endotypes of chronic rhinosinusitis based on cluster analysis of biomarkers. J Allergy Clin Immunol 2016; 137: $1449-1456$ e4

[172] De Greve G et al. Endotype-driven treatment in chronic upper airway diseases. Clin Transl Allergy 2017; 7: 22

[173] Akdis CA.et al. Endotypes and phenotypes of chronic rhinosinusitis: a PRACTALL document of the European Academy of Allergy and Clinical Immunology and the American Academy of Allergy, Asthma \& Immunology. J Allergy Clin Immunol 2013; 131: 1479-1490

[174] Schmitt J et al. Allergy immunotherapy for allergic rhinitis effectively prevents asthma: Results from a large retrospective cohort study. J Allergy Clin Immunol 2015; 136: 1511-1516

[175] Hopkins C, Andrews P, Holy CE. Does time to endoscopic sinus surgery impact outcomes in chronic rhinosinusitis? Retrospective analysis using the UK clinical practice research data. Rhinology 2015; 53: $18-24$

[176] Benninger MS et al. Impact of medically recalcitrant chronic rhinosinusitis on incidence of asthma. Int Forum Allergy Rhinol 2016; 6: $124-129$

[177] Hopkins C, Rimmer ], Lund V]. Does time to endoscopic sinus surgery impact outcomes in Chronic Rhinosinusitis? Prospective findings from the National Comparative Audit of Surgery for Nasal Polyposis and Chronic Rhinosinusitis. Rhinology 2015; 53: 10-17

[178] Benninger MS et al. Early versus delayed endoscopic sinus surgery in patients with chronic rhinosinusitis: impact on health care utilization. Otolaryngol Head Neck Surg 2015; 152: 546-552 
[179] Stuck BA et al. Guideline for "rhinosinusitis"-long version: S2k guideline of the German College of General Practitioners and Family Physicians and the German Society for Oto-Rhino-Laryngology, Head and Neck Surgery. HNO 2017

[180] Messerklinger W. The ethmoidal infundibulum and its inflammatory illnesses (author's transl). Arch Otorhinolaryngol 1979; 222: 11-22

[181] Stammberger H, Posawetz W. Functional endoscopic sinus surgery. Concept, indications and results of the Messerklinger technique. Eur Arch Otorhinolaryngol 1990; 247: 63-76

[182] Rimmer J et al. Surgical versus medical interventions for chronic rhinosinusitis with nasal polyps. Cochrane Database Syst Rev 2014; CD006991

[183] Sharma R et al. Surgical interventions for chronic rhinosinusitis with nasal polyps. Cochrane Database Syst Rev 2014; CD006990

[184] Rudmik L et al. Topical therapies in the management of chronic rhinosinusitis: an evidence-based review with recommendations. Int Forum Allergy Rhinol 2013; 3: 281-298

[185] Kalish L et al. WITHDRAWN: Topical steroids for nasal polyps. Cochrane Database Syst Rev 2016; 4: CD006549

[186] Chong LY et al. Intranasal steroids versus placebo or no intervention for chronic rhinosinusitis. Cochrane Database Syst Rev 2016; 4: CD011996

[187] Chong LY et al. Different types of intranasal steroids for chronic rhinosinusitis. Cochrane Database Syst Rev 2016; 4: CD011993

[188] Tokunaga T et al. Novel scoring system and algorithm for classifying chronic rhinosinusitis: the JESREC Study. Allergy 2015; 70: 995-1003

[189] Hellings PW et al. Uncontrolled allergic rhinitis and chronic rhinosinusitis: where do we stand today? Allergy 2013; 68: 1-7

[190] Philpott $C$ et al. The burden of revision sinonasal surgery in the UK-data from the Chronic Rhinosinusitis Epidemiology Study (CRES): a cross-sectional study. BMJ Open 2015; 5: e006680

[191] Nabi $S$ et al. Nasal spray adherence after sinus surgery: problems and predictors. J Otolaryngol Head Neck Surg 2012; 41: (Suppl 1): S49-S55

[192] Bousquet J et al. Unmet needs in severe chronic upper airway disease (SCUAD). J Allergy Clin Immunol 2009; 124: 428-433

[193] Ishizaka K, Ishizaka T, Hornbrook MM. Allergen-binding activity of gamma-E, gamma-G and gamma-A antibodies in sera from atopic patients. In vitro measurements of reaginic antibody. I Immunol 1967; 98: 490-501

[194] Johansson SG, Bennich H. Immunological studies of an atypical (myeloma) immunoglobulin. Immunology 1967; 13: 381-394

[195] Johansson SG. Raised levels of a new immunoglobulin class (IgND) in asthma. Lancet 1967; 2: 951-953

[196] Ring J, Bergmann C. Geschichte der Allergologie. Biedermann, Heppt, Renz, Röcken: Allergologie 2016; 1: 3-9

[197] Casale TB et al. Effect of omalizumab on symptoms of seasonal allergic rhinitis: a randomized controlled trial. JAMA 2001; 286: 2956-2967

[198] Chervinsky P et al. Omalizumab, an anti-IgE antibody, in the treatment of adults and adolescents with perennial allergic rhinitis. Ann Allergy Asthma Immunol 2003; 91: 160-167

[199] Kopp MV et al. The effect of anti-IgE treatment on in vitro leukotriene release in children with seasonal allergic rhinitis. J Allergy Clin Immunol 2002; 110: 728-735

[200] Klunker $S$ et al. Combination treatment with omalizumab and rush immunotherapy for ragweed-induced allergic rhinitis: Inhibition of IgE-facilitated allergen binding. J Allergy Clin Immunol 2007; 120: 688-695

[201] Kopp MV et al. Combination of omalizumab and specific immunotherapy is superior to immunotherapy in patients with seasonal allergic rhinoconjunctivitis and co-morbid seasonal allergic asthma. Clin Exp Allergy 2009; 39: 271-279
[202] MacGinnitie A] et al. Omalizumab facilitates rapid oral desensitization for peanut allergy. J Allergy Clin Immunol 2017; 139: 873-881 e8

[203] Kopp MV. Role of immunmodulators in allergen-specific immunotherapy. Allergy 2011; 66: 792-797

[204] Akdis CA, Akdis M. Mechanisms and treatment of allergic disease in the big picture of regulatory T cells. J Allergy Clin Immunol 2009; 123: 735-746 quiz 747-748

[205] Mobs C et al. Birch pollen immunotherapy results in long-term loss of Bet v 1-specific TH2 responses, transient TR1 activation, and synthesis of IgE-blocking antibodies. J Allergy Clin Immunol 2012; 130: 1108-1116 e6

[206] Wambre E et al. Differentiation stage determines pathologic and protective allergen-specific CD4 + T-cell outcomes during specific immunotherapy. J Allergy Clin Immunol 2012; 129: 544-551 551 e1-e7

[207] Gabrielsson S et al. Specific immunotherapy prevents increased levels of allergen-specific IL-4- and IL-13-producing cells during pollen season. Allergy 2001; 56: 293-300

[208] Michaud B et al. Quantification of circulating house dust mite-specific IL-4- and IL-13-secreting T cells correlates with rhinitis severity in asthmatic children and varies with the seasons. Clin Exp Allergy 2014; 44: $222-230$

[209] Francis JN, Till S], Durham SR. Induction of IL-10 + CD4 + CD25 + T cells by grass pollen immunotherapy. J Allergy Clin Immunol 2003; 111: $1255-1261$

[210] Radulovic $S$ et al. Grass pollen immunotherapy induces Foxp3expressing CD4 + CD25 + cells in the nasal mucosa. J Allergy Clin Immunol 2008; 121: 1467-1472 1472 e1

[211] Robinson DS, Larche M, Durham SR. Tregs and allergic disease. J Clin Invest 2004; 114: 1389-1397

[212] Till S et al. IL-5 production by allergen-stimulated T cells following grass pollen immunotherapy for seasonal allergic rhinitis. Clin Exp Immunol 1997; 110: 114-121

[213] Yang $M$ et al. Interleukin-13 mediates airways hyperreactivity through the IL-4 receptor-alpha chain and STAT-6 independently of IL-5 and eotaxin. Am J Respir Cell Mol Biol 2001; 25: 522-530

[214] Mantel PY et al. GATA3-driven Th2 responses inhibit TGF-beta1induced FOXP3 expression and the formation of regulatory $T$ cells. PLoS Biol 2007; 5 (e329)

[215] Chaker AM et al. Short-term subcutaneous grass pollen immunotherapy under the umbrella of anti-IL-4: a randomized controlled trial. J Allergy Clin Immunol 2016; 137: 452-461 e9

[216] Johansson SG. IgE in allergic diseases. Proc R Soc Med 1969; 62: 975-976

[217] Donovan R et al. Immunoglobulins in nasal polyp fluid. Int Arch Allergy Appl Immunol 1970; 37: 154-166

[218] Whiteside TL et al. The presence of IgE on the surface of lymphocytes in nasal polyps. J Allergy Clin Immunol 1975; 55: 186-194

[219] Van Zele T et al. Staphylococcus aureus colonization and IgE antibody formation to enterotoxins is increased in nasal polyposis. J Allergy Clin Immunol 2004; 114: 981-983

[220] Penn R, Mikula S. The role of anti-IgE immunoglobulin therapy in nasal polyposis: a pilot study. Am J Rhinol 2007; 21: 428-432

[221] Guglielmo M et al. Recalcitrant nasal polyposis: achievement of total remission following treatment with omalizumab. J Investig Allergol Clin Immunol 2009; 19: 158-159

[222] Vennera Mdel C et al. Efficacy of omalizumab in the treatment of nasal polyps. Thorax 2011; 66: 824-825

[223] Pinto JM et al. A randomized, double-blind, placebo-controlled trial of anti-IgE for chronic rhinosinusitis. Rhinology 2010; 48: 318-324

[224] Gevaert $P$ et al. Omalizumab is effective in allergic and nonallergic patients with nasal polyps and asthma. J Allergy Clin Immunol 2013; 131: $110-116$ e1 
[225] Lowe P], Renard D. Omalizumab decreases IgE production in patients with allergic (IgE-mediated) asthma; PKPD analysis of a biomarker, total IgE. Br J Clin Pharmacol 2011; 72: 306-320

[226] Castro M et al. Reslizumab for poorly controlled, eosinophilic asthma: a randomized, placebo-controlled study. Am J Respir Crit Care Med 2011; 184: 1125-1132

[227] Haldar P et al. Mepolizumab and exacerbations of refractory eosinophilic asthma. N Engl J Med 2009; 360: 973-984

[228] Nair P et al. Mepolizumab for prednisone-dependent asthma with sputum eosinophilia. N Engl J Med 2009; 360: 985-993

[229] Gevaert P et al. Mepolizumab, a humanized anti-IL-5 mAb, as a treatment option for severe nasal polyposis. J Allergy Clin Immunol 2011; 128: 989-995 e1-e8

[230] Bachert C et al. Reduced need for surgery in severe nasal polyposis with mepolizumab: Randomized trial. J Allergy Clin Immunol 2017; 140: 1024-1031 e14

[231] Casale TB. Biologics and biomarkers for asthma, urticaria, and nasal polyposis. J Allergy Clin Immunol 2017; 139: 1411-1421

[232] Wenzel $S$ et al. Dupilumab in persistent asthma with elevated eosinophil levels. N Engl J Med 2013; 368: 2455-2466

[233] Beck LA et al. Dupilumab treatment in adults with moderate-tosevere atopic dermatitis. N Engl J Med 2014; 371: 130-139

[234] Simpson EL et al. Two Phase 3 Trials of Dupilumab versus Placebo in Atopic Dermatitis. N Engl J Med 2016; 375: 2335-2348

[235] Jung YG et al. Predictive capabilities of serum eosinophil cationic protein, percentage of eosinophils and total immunoglobulin $\mathrm{E}$ in allergic rhinitis without bronchial asthma. J Int Med Res 2011; 39: 2209-2216

[236] Shamji MH et al. Biomarkers for monitoring clinical efficacy of allergen immunotherapy for allergic rhinoconjunctivitis and allergic asthma: an EAACI Position Paper. Allergy 2017; 72: 1156-1173

[237] Kim SH et al. Dipeptidyl-peptidase 10 as a genetic biomarker for the aspirin-exacerbated respiratory disease phenotype. Ann Allergy Asthma Immunol 2015; 114: 208-213

[238] Dietz K et al. Age dictates a steroid-resistant cascade of Wnt5a, transglutaminase 2, and leukotrienes in inflamed airways. J Allergy Clin Immunol 2017; 139: 1343-1354.e6

[239] Boscke R et al. Wnt Signaling in Chronic Rhinosinusitis with Nasal Polyps. Am J Respir Cell Mol Biol 2017; 56: 575-584
[240] Zissler UM et al. Current and future biomarkers in allergic asthma. Allergy 2016; 71: 475-494

[241] Corren J et al. Lebrikizumab treatment in adults with asthma. N Engl J Med 2011; 365: 1088-1098

[242] Bujarski S, Parulekar AD, Hanania NA. Lebrikizumab in the treatment of asthma. Expert Opin Biol Ther 2016

[243] Hanania NA et al. Efficacy and safety of lebrikizumab in patients with uncontrolled asthma (LAVOLTA I and LAVOLTA II): replicate, phase 3, randomised, double-blind, placebo-controlled trials. Lancet Respir Med 2016; 4: 781-796

[244] De Schryver E et al. The effect of systemic treatments on periostin expression reflects their interference with the eosinophilic inflammation in chronic rhinosinusitis with nasal polyps. Rhinology 2017; 55: 152-160

[245] Gevaert P et al. Nasal IL-5 levels determine the response to anti-IL-5 treatment in patients with nasal polyps. J Allergy Clin Immunol 2006; 118: $1133-1141$

[246] Matricardi PM et al. EAACI Molecular Allergology User's Guide. Pediatr Allergy Immunol 2016; 27: (Suppl 23): 1-250

[247] Klimek L, Becker S. Molecular component-resolved allergy diagnostics in ENT. HNO 2017; 65: 818-825

[248] Chaker AM, Klimek L. Individualized, personalized and stratified medicine: a challenge for allergology in ENT?. HNO 2015; 63: 334-342

[249] Ethikrat Deutschland, Forum Bioethik: Die Medizin nimmt's persönlich. 2009 (http://www.ethikrat.org/dateien/pdf/fb_2009-0624_simultanmitschrift.pdf am 04.01.2018)

[250] Muller-Berghaus ] et al. Special considerations for the regulation of biological medicinal products in individualised medicine. More than stratified medicine. Bundesgesundheitsblatt Gesundheitsforschung Gesundheitsschutz 2013; 56: 1538-1544

[251] Green RC, Lautenbach D, McGuire AL. GINA, genetic discrimination, and genomic medicine. N Engl J Med 2015; 372: 397-399

[252] Siest G. Systems medicine, stratified medicine, personalized medicine but not precision medicine. Drug Metabol Drug Interact 2014; 29: 1-2 